\title{
Magnetic Resonance Imaging in Multiple Sclerosis
}

\author{
Christopher C. Hemond and Rohit Bakshi \\ Laboratory for Neuroimaging Research, Partners Multiple Sclerosis Center, Ann Romney Center for Neurologic \\ Diseases, Departments of Neurology and Radiology, Brigham and Women's Hospital, Harvard Medical School, \\ Boston, Massachusetts 02115 \\ Correspondence: rbakshi@post.harvard.edu
}

Since its technical development in the early 1980s, magnetic resonance imaging (MRI) has quickly been adopted as an essential tool in supporting the diagnosis, longitudinal monitoring, evaluation of therapeutic response, and scientific investigations in multiple sclerosis (MS). The clinical usage of MRI has increased in parallel with technical innovations in the technique itself; the widespread adoption of clinically routine MRI at 1.5T has allowed sensitive qualitative and quantitative assessments of macroscopic central nervous system (CNS) inflammatory demyelinating lesions and tissue atrophy. However, conventional MRI lesion measures lack specificity for the underlying MS pathology and only weakly correlate with clinical status. Higher field strength units and newer, advanced MRI techniques offer increased sensitivity and specificity in the detection of disease activity and disease severity. This review summarizes the current status and future prospects regarding the role of MRI in the characterization of MS-related brain and spinal cord involvement.

$T^{\mathrm{h}}$ he introduction of magnetic resonance imaging (MRI) in the early 1980s revolutionized the diagnosis and treatment of multiple sclerosis (MS) by allowing unprecedented in vivo visualization of lesional activity and burden. As the technology improved over the next three decades, MRI quickly grew to become the single most important paraclinical diagnostic and monitoring tool available; continual technical advances have helped elucidate neuroinflammatory disease mechanisms in ways that are highly complementary to histopathological and immunological methods. MRI has furthermore emerged as a key supportive outcome measure in MS clinical trials (Neema et al. 2007b), and is routinely used for longitudinal clinical monitor- ing. MRI has a major role in establishing the diagnosis of MS; the disease can now be confirmed with a single time point MRI scan by the most recent International Panel on MS Diagnosis criteria (Polman et al. 2011).

Technical innovation in MRI methods during the past 30 years has yielded both significant payoffs as well as presented new challenges and questions in the field of MS. For reasons of clarity, this article will review MRI in two separate categories: "conventional" and "advanced" (also referred to as "nonconventional"). Conventional MRI can be thought of as the set of widely available, well-characterized, and highly standardized MRI protocols, which were initially incorporated into diagnostic criteria with the first set of guide-

Editors: Howard L. Weiner and Vijay K. Kuchroo

Additional Perspectives on Multiple Sclerosis available at www.perspectivesinmedicine.org

Copyright (C) 2018 Cold Spring Harbor Laboratory Press; all rights reserved; doi: 10.1101/cshperspect.a028969

Cite this article as Cold Spring Harb Perspect Med 2018;8:a028969 
lines from the International Panel (McDonald et al. 2001). These protocols include T2-weighted, fluid-attenuated inversion recovery (FLAIR), or short-tau inversion recovery (STIR), and T1weighted pre- and postgadolinium contrast pulse sequences, at magnetic field strengths of $1.5 \mathrm{~T}$ in both the brain and spinal cord. These MRI sequences are routinely used for clinical decisionmaking. Advanced MRI at higher magnetic field strengths (e.g., 3T and 7T) offers higher signalto-noise ratios and enhanced spatial resolution as small as $100 \mu \mathrm{m}$, but at the expense of increased artifacts, lack of standardization across institutions, and higher cost (Sinnecker et al. 2015). A large number of advanced MRI pulse sequences have been used to increase the specificity of MS diagnosis and will be reviewed here as well, such as magnetization transfer (MT), magnetic resonance spectroscopy (MRS), diffusion-weighted imaging, and novel contrast agents.

Despite high diagnostic sensitivity, conventional MRI lacks specificity for MS, and is limited in metrics needed for clinical validation and prognostication. Conventional MRI is frequently incapable of distinguishing ongoing pathology in normal-appearing white matter (NAWM), despite known disease processes as described with histopathological correlation. Advanced MRI offers to the opportunity to increase diagnostic precision for the underlying MS pathological processes, and improve clinical correlations and prediction of the accumulation of disability. Unfortunately, these advanced MRI techniques remain limited in practical clinical usage because of variability in the availability of hardware, scan protocols, and other technical variables across institutions. This article will provide a review regarding the role of conventional MRI in MS, as well as an overview of advanced MRI techniques that have the potential to improve clinical care and give additional insight into pathological disease mechanisms for scientific investigations of MS.

\section{T2-WEIGHTED SPIN-ECHO AND INVERSION-RECOVERY SEQUENCES}

The standard sequences used to identify MS lesions in the brain and spinal cord are sensitive to
T2 prolongation, leading to a hyperintense appearance. The most common such sequences used for brain MRI include heavily weighted fast spin-echo T2-weighted and FLAIR sequences. Occasionally, particularly with older imaging platforms, early echo (proton density) images may also be used. T2 hyperintense MS lesions tend to form around centripetal parenchymal veins and venules, and thus have a propensity to affect certain areas in the brain and the spine. This observation is reflected in the most recent International Panel diagnostic criteria for MS, which requires, for the demonstration of dissemination in space, the presence of one or more $\mathrm{T} 2$ hyperintense lesions in at least two of four areas in the central nervous system (CNS), including (1) periventricular white matter (WM) regions, (2) juxtacortical gray-white junction, (3) infratentorial brain regions, and (4) spinal cord (Polman et al. 2011). International consensus from a recent imaging consortium recommended the addition of the optic nerve as a fifth area of consideration to increase diagnostic sensitivity and specificity (Filippi et al. 2016). Some spatial patterns of T2 hyperintense plaques are quite specific for MS, such as the socalled "Dawson's fingers" pattern (Fig. 1), with radially oriented, finger-like perivenular lesions adjacent to and parallel to the long axis of the lateral ventricles of the brain. Typical T2 lesions are oval/ovoid in shape and larger than $5 \mathrm{~mm}$ in diameter at $1.5 \mathrm{~T}$.

Various pulse sequences can improve contrast for identifying small T2 hyperintense MS lesions depending on location. Conventional T2-weighted sequences remain the most sensitive for detection of lesions in the brainstem and cerebellum because of resilience to flow-related artifacts, whereas FLAIR is more sensitive to the detection of periventricular and cortical/juxtacortical lesions (Geurts et al. 2005a; Neema et al. 2007b; Vural et al. 2013). As a general principle, the higher the field strength of the MRI, the higher the signal-to-noise and subsequently the sensitivity of the scan to detect lesions (Wattjes et al. 2006; Wattjes and Barkhof 2009; Stankiewicz et al. 2011).

The primary drawback in the consideration of T2 hyperintense lesions is the lack of specif- 

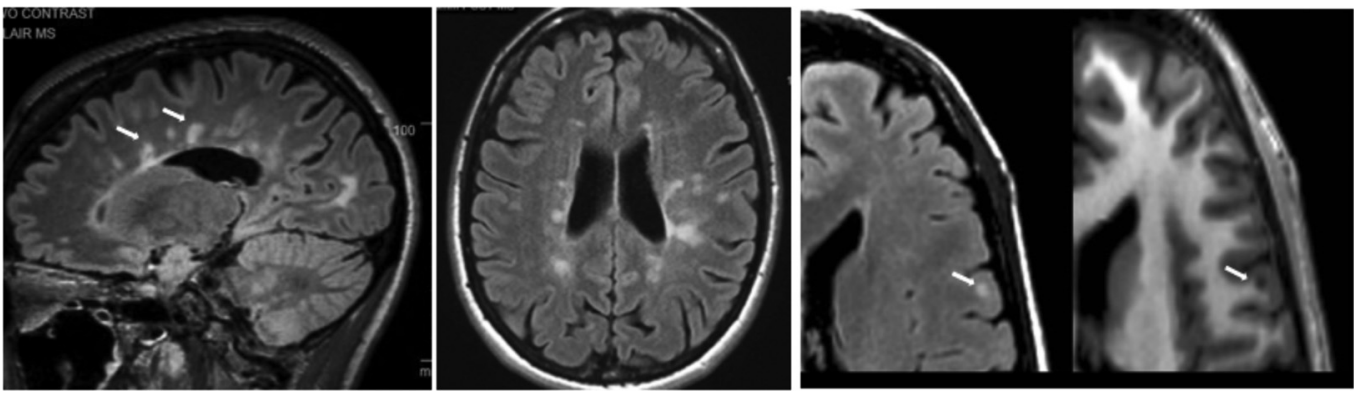

Figure 1. Typical multiple sclerosis (MS) white matter and gray matter lesions in the brain as shown by cerebral 3T magnetic resonance imaging (MRI). (Left and middle panel) White matter lesions from a 40-year-old woman with relapsing-remitting MS (RRMS), showing 3D sagittal fluid-attenuated inversion recovery (FLAIR, left panel) and 2D axial FLAIR (middle panel). Note the perivenular "Dawson's fingers" orientation of lesions (arrows, left panel) and numerous periventricular lesions with ovoid/oval predominant configuration on both images. (Right panel) High-resolution FLAIR and a coregistered 3D-modified driven-equilibrium Fourier transform (MDEFT) scans showing a FLAIR hyperintense lesion (arrow) that is MDEFT hypointense (arrow) and involves the cerebral cortex in a 29 -year-old man with RRMS.

icity for lesion severity and the nature of the underlying MS pathology; such lesions can represent a wide range of pathologic processes, including inflammation, demyelination, remyelination, gliosis, edema, Wallerian degeneration, and axonal damage (Brück et al. 1997). Occasionally, these lesions will be self-limited and transitory (Meier et al. 2007); the majority, however, will remain permanently, especially if gadolinium enhancing (see Fig. 2). Interestingly, although highly characteristic of the disease, T2 hyperintense lesion number and volumes show only modest and unreliable correlations with clinical status as measured by cognitive dysfunction and neurologic impairment on the expanded disability status scale (EDSS). These observations have led to a clinical MRI paradox in linking imaging findings to clinical status (Filippi and Rocca 2007). T2 hyperintense lesions nonetheless form the cornerstone of diagnosis, are a standard supportive outcome measure to monitor therapeutic efficacy in clinical trials (Neema et al. 2007b), and have modest but significant value in predicting conversion from a clinically isolated syndrome (CIS) to clinically definite MS (Brex et al. 2002).

It is now well accepted that disease-modifying therapies (DMTs) can effectively reduce both clinical relapse rate as well as the accrual rate of T2 hyperintense lesions in relapsing forms of MS. Earlier generation self-injectables such as interferon (INF)- $\beta$ and glatiramer acetate (GA) reduce T2 hyperintense lesion volume by at least $30 \%$ compared with placebo measured at several months to a few years (Comi et al. 2001; Bakshi et al. 2005b; Marziniak and Meuth 2014); newer oral and intravenous (IV) infusion agents show somewhat higher magnitudes of treatment effects on such lesions (Nicholas et al. 2012).

\section{T1-WEIGHTED SPIN-ECHO AND GRADIENT-ECHO IMAGING AND BLOOD- BRAIN BARRIER (BBB) COMPROMISE}

T1-weighted pulse sequences measure longitudinal magnetization and provide excellent structural definition, such as contrast between fatpredominant structures (i.e., myelin) that are seen as bright, and water-predominant structures (i.e., cortex) that appear dark. Pathological processes such as demyelination and axonal loss destroy the fat content of axonal structures and increase water content, both of which are consequently seen as hypointense areas on T1 images. T1-weighted pulse sequences frequently used in the routine evaluation of MS include spin-echo (T1SE) and gradient-echo (T1GE), both of which may be used to assess for the presence of enhancement after gadolinium administra- 


\section{C.C. Hemond and R. Bakshi}

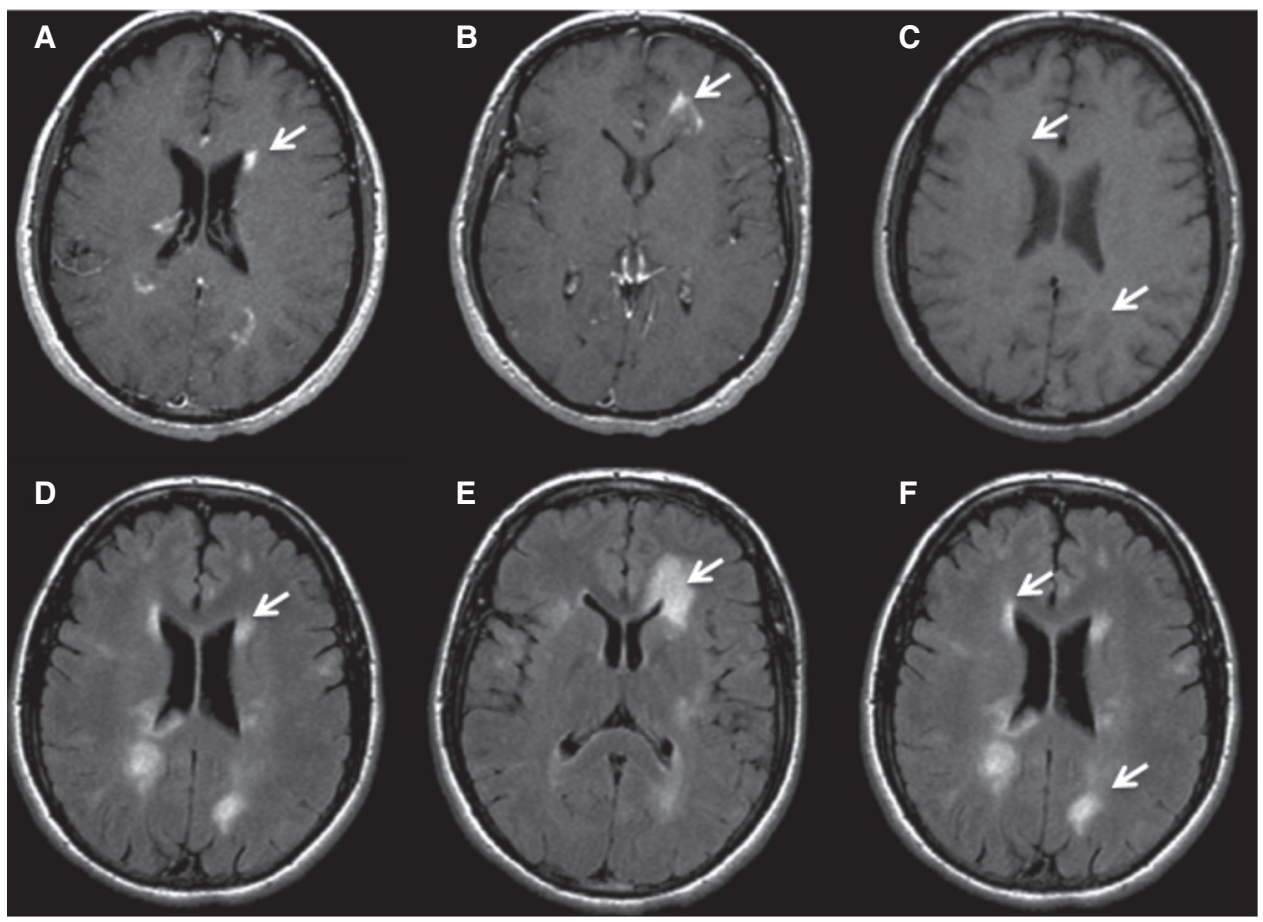

Figure 2. T1-weighted spin-echo images to detect white matter lesions in multiple sclerosis (MS). Cerebral 1.5T magnetic resonance imaging (MRI) scans showing typical MS findings. (A) T1-weighted spin-echo (T1SE) postcontrast image showing a typical homogeneous gadolinium-enhancing lesion (arrow) corresponding to a hyperintense lesion (arrow) on the fluid-attenuated inversion recovery (FLAIR) scan (D). Also note in $A$ two posterior open-ring enhancing lesions. $(B)$ T1SE postcontrast image showing a heterogeneous/atypical gadolinium-enhancing lesion (arrow) corresponding to a large hyperintense lesion (arrow) on FLAIR (E). (C) T1SE noncontrast scan showing hypointense lesions (arrows) corresponding to hyperintense lesions (arrows) on FLAIR $(F)$. Note in $C$, the anterior lesion has more prominent hypointensity than the posterior lesion. These images are from a 24-year-old man with clinically active relapsing-remitting MS.

tion. Spin-echo images are most commonly used at 1.5T; gradient-echo images are most commonly used at 3T. In healthy individuals, intravenously administered gadolinium contrast is sequestered mostly within the vascular structures of the brain, and shortens the $\mathrm{T} 1$ relaxation time to reveal arteries and veins as hyperintense.

In early stages of patients with relapsing forms of MS, acute inflammatory events related to adaptive immunity regularly recur (Weiner 2009) and can be longitudinally characterized through phases of evolution with MRI. In an acute inflammatory phase, an unknown pathological event triggers localized CNS inflammation, with breakdown of the $\mathrm{BBB}$, and extravasation of gadolinium contrast into the surrounding parenchyma (Fig. 2). This event is concurrent with localized lymphocyte entry into the CNS (Minagar and Alexander 2003). It remains unclear whether this vascular disruption is a result of direct damage to the endothelium, or rather secondary to parenchymal damage with consequent inflammation and increased vascular permeability (Waubant 2006). A majority of the time, gadolinium-enhancing lesions are accompanied by $\mathrm{T} 1$ hypointensity (Rovira et al. 2013), also known as "black holes" (BHs), that likely reflect a combination of demyelination and edema with their first appearance (Fig. 2). This acute phase of gadolinium positivity lasts on average 3 weeks (range: 2 to 12 weeks) (Cotton et al. 2003). Improved sensitivity of lesions can be obtained by using increased dosages of gadolinium, higher strength magnetic 
fields, or several minutes of delay following injection of contrast to allow greater tissue penetration (Neema et al. 2007b); a 5-min delay is recommended to balance sensitivity and practical considerations.

Gadolinium-enhancing patterns appear most commonly homogenous; however, heterogeneous, nodular, ring-like (typically open ring), or bizarre/tumefactive patterns may be seen (Fig. 2) (Masdeu et al. 1996, 2000; Minneboo et al. 2005). In a study evaluating the dynamics of contrast-enhancing lesions in MS (Gaitann et al. 2011), serially scanned gadolinium-positive lesions during a 30 - to 60-min interval showed that the larger ring-like lesions enhanced centripetally (inward), whereas the smaller nodular lesions always enhanced centrifugally (outward), with some evolving into ringlike lesions before resolution. Although ring-like lesions tend to show greater short-term tissue destruction and edema (Rovira et al. 1999) and resolve more slowly (Minneboo et al. 2005), both patterns may ultimately leave similar long-term footprints at 1 year (Davis et al. 2010). Gadolinium-enhancing lesions are five to ten times more common than clinical relapses, are often clinically silent, and correlate only weakly with disability (McFarland 2009). However, their presence is a marker for ongoing disease activity (Molyneux et al. 1998) and increases the risk of clinical relapse in the short term (Kappos et al. 1999). The presence of gadolinium-enhancing lesions is a common outcome measure in clinical trials. In later stages of relapsing-remitting MS (RRMS) and in progressive forms of the disease, gadolinium enhancement of parenchymal lesions is much less common; this is thought to represent a switch to innate rather than adaptive immunity as the main driving force for disease worsening (Weiner 2009).

Following the acute phase of gadolinium enhancement, the BBB is repaired and a 3- to 6month subacute phase of lesion evolution begins. Resorption of edema and remyelination may occur early, although in individual patients and individual lesions, the degree of repair capacity is variable; this is a shift to more severe lesions and may herald the onset of a progressive stage of the disease (Rovira et al. 2013). About
Magnetic Resonance Imaging in Multiple Sclerosis

$40 \%-60 \%$ of the acute T1-hypointensities associated with gadolinium-enhancing lesions will return to T1 isointense tissue within 6 to 12 months. However, the remaining lesions persist as chronic BHs (Minneboo et al. 2005) and are typically confined to the supratentorial areas; these reflect severe irreversible demyelination and axonal loss (Truyen et al. 1996; Bitsch et al. 2001; Fisher et al. 2007). Histologic correlation has indicated that the more profound the $\mathrm{T} 1$ hypointensity in the persistent $\mathrm{BH}$, the greater the loss of axonal density and matrix destruction (van Walderveen et al. 1998). The risk of conversion from acute to chronic $\mathrm{BHs}$ may be increased with larger lesions and a longer duration of enhancement (Bagnato et al. 2003); secondary-progressive MS (SPMS) tends to show a higher $\mathrm{BH}$ burden versus relapsing MS (van Walderveen et al. 2001). Both older and newer-generation DMTs have been shown to reduce the formation and conversion rate of acute gadolinium-enhancing lesions to chronic BHs (Filippi et al. 2001; Nicholas et al. 2012; Marziniak and Meuth 2014; Oommen et al. 2016).

The reasons for significant variability in subacute phase $\mathrm{T} 1 \mathrm{BH}$ evolution are likely manifold, including methodological differences in imaging techniques (e.g., spin-echo and gradient-echo are not interchangeable in the characterization of BHs) (Dupuy et al. 2015). Other factors include subjective lesion thresholds, variable patient populations, disease subtypes, and disease durations (Sahraian et al. 2010). This variability in the definition of BHs creates methodological challenges for cross-sectional studies especially, and has likely contributed to inconsistent correlations with clinical status. These limitations can be at least partially overcome with longitudinal studies (Filippi et al. 2001; Dalton et al. 2004), using a T1/T2 lesion ratio for each patient (Bakshi et al. 2008) or quantifying the intensity of a BH (Thaler et al. 2015). Nonetheless, there is widespread acceptance of the concept that global cerebral burden of $\mathrm{BHs}$ tends to correlate with neurological disability better than T2 hyperintense lesion load (Sahraian et al. 2010). T1 hypointense lesions are common supportive outcome measures in mul- 
tiple MS therapeutic trials (Molyneux et al. 2000; Neema et al. 2007b).

Of note, several health concerns have arisen regarding gadolinium contrast agents. One clear risk is seen in patients with advanced kidney failure, in whom these agents have been associated with a potentially fatal condition known as nephrogenic systemic fibrosis (Broome et al. 2007). Newer gadolinium agents are now used, which likely reduce the risk of toxicity; however, poor kidney function is a significant contraindication for use of these agents. Additionally, persistent gadolinium deposits have been observed in the deep grey nuclei of humans exposed to repeated contrast administration. The possible health effects of these findings remain unclear (Stojanov et al. 2016). Therefore, the decision to use gadolinium in routine MS care should be individualized.

\section{BRAIN ATROPHY/NEURODEGENERATION}

Widespread brain and spinal cord atrophy has emerged as a core manifestation and highly relevant finding in MS. The relationship between brain WM lesions and brain atrophy remains significant but weak (Tauhid et al. 2014). Several lines of evidence support a neurodegenerative component of the disease process that is somewhat independent of inflammatory demyelination (Calabrese et al. 2015). Aside from tissue loss caused by locally destructive WM lesions and secondary "dying-back" with tract-specific axonal and neuronal loss, a variety of other potential mechanisms include iron accumulation, mitochondrial damage, microglia activation, and oxidative stress (Mahad et al. 2015). Observed longitudinally, all components of the CNS - including the brain, optic nerve, and spinal cord-experience irreversible tissue loss at a higher rate than expected with normal aging. Brain atrophy begins early in the disease process, and progresses annually in untreated patients at a rate of $0.5 \%-1.0 \%$ per year, independent of clinical subtype (Fig. 3) (De Stefano et al. 2010; Radue et al. 2013). Spinal cord atrophy can also be severe, and will be discussed below. Remarkably, global brain atrophy can be observed even at preclinical stages of MS (De Stefano et al.
2011; Azevedo et al. 2015; Rojas et al. 2015; Labiano-Fontcuberta et al. 2016) as at the time of first symptoms (Bermel and Bakshi 2006; Henry et al. 2008). Atrophy bears the closest relationship to physical disability and cognitive impairment versus standard lesional MRI metrics (e.g., T1 hypointense, T2 hyperintense, and gadolinium-enhancing lesions) (Bermel and Bakshi 2006; Amato et al. 2007; Tedeschi et al. 2009; Radue et al. 2015). Because brain atrophy has been shown to have such high clinical relevance, it is now regularly incorporated as a standard clinical outcome measure in large therapeutic trials (De Stefano et al. 2014; Radue et al. 2015; Tsivgoulis et al. 2015); existing data show that both new- and old-generation DMTs reduce the rate of brain atrophy as measured at 2 or more years (Ziemssen et al. 2015). A meta-analysis including only randomized placebo-controlled trials with interferons, GA, and fingolimod additionally confirmed a linear attenuation of brain atrophy during a 2-year study period (Tsivgoulis et al. 2015).

Brain atrophy can be readily measured using a wide variety of MRI methods. Qualitatively, atrophy can best be appreciated as the enlargement of the intracranial cerebrospinal fluid (CSF) spaces in conjunction with reductions in tissue volume. Atrophy can be simplistically quantified in clinical settings by measuring ventricular width, corpus callosum area in cross-section, or intercaudate distance (Bakshi et al. 2005a). For more efficient and reproducible measurements in the research and clinical trials setting, fully automated computer segmentation techniques relying on high-resolution T1-weighted images are typically applied; many of these techniques also allow the separate compartment-specific assessment of WM versus gray matter (GM) and regional atrophy (Bermel and Bakshi 2006). Results should be interpreted with caution however, as CNS volume is susceptible to MS-unrelated factors such as medications, diurnal variations, and hydration status, as well as MS-related edema, inflammation, and gliosis, which occur to a greater extent in WM compared with GM (Bermel and Bakshi 2006; Nakamura et al. 2015).

Atrophy studies have been important in showing the involvement of GM in MS. For ex- 

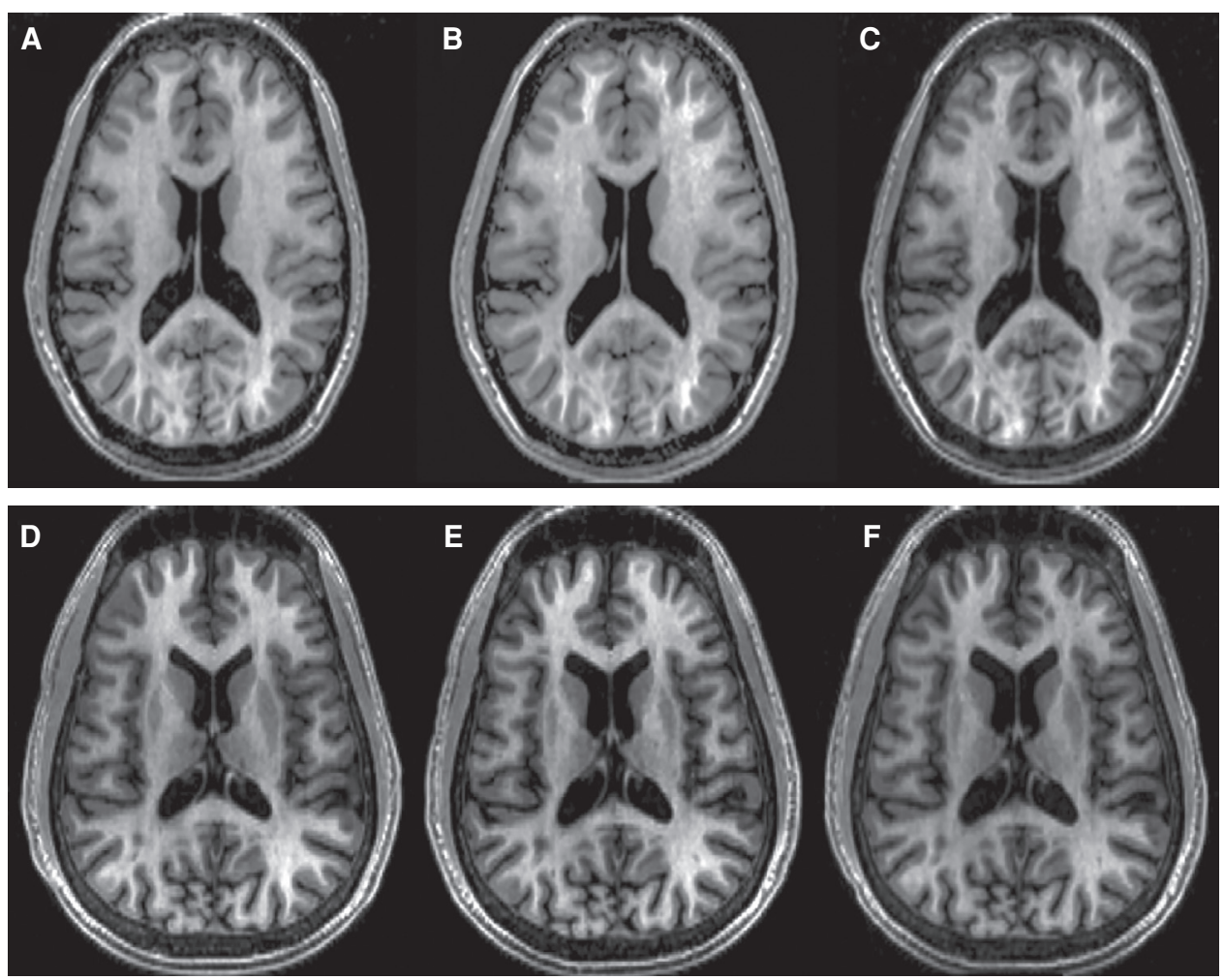

Figure 3. Quantitative serial 3T magnetic resonance imaging (MRI) analysis depicting mild (top) and severe (bottom) brain atrophy rates. All images are high-resolution 3D-modified driven-equilibrium Fourier transform (MDEFT) sequences in the axial plane. Top row shows subtle, mild progressive atrophy in a 56-year-old woman with relapsing remitting multiple sclerosis (RRMS) at $(A)$ baseline, $(B) 3$ years, and $(C) 5$ years. Using the fully automated SIENA package (fsl.fmrib.ox.ac.uk/fsl/fslwiki/SIENA), her whole-brain percent brain volume change is $0.28 \%$ per year. A more severe atrophy rate is shown in the bottom row in a 29 -year-old man with RRMS at $(D)$ baseline, $(E) 2$ years, and $(F) 4$ years. SIENA demonstrates a whole-brain percent volume change of $0.79 \%$ per year, at least two to five times higher than the healthy expected rate of someone his age.

ample, in early MS, studies have shown a selective reduction in GM volume rather than WM volume loss (Pirko et al. 2007, Rojas et al. 2015); further, this GM atrophy correlates with physical and cognitive disability to a higher degree than does lesion load, or whole-brain or WM atrophy (Sanfilipo et al. 2006; Fisher et al. 2008).

Focal GM atrophy as measured by volumetric analysis strongly correlates with functional deficits (Grassiot et al. 2009). For example, thalamic atrophy more strongly correlates with cognitive disability compared to cortical GM volume in RRMS (Wylezinska et al. 2003) and CIS (Steckova et al. 2014). Deep gray nuclei volume loss is proportionately higher than is atrophy of the cerebral GM or the whole brain (Bermel et al. 2003; Houtchens et al. 2007). Cortical thickness analyses (Fischl and Dale 2000) reveals consistent atrophy patterns in MS including the frontal and temporal lobes (Bermel and Bakshi 2006); these results agree with prior reports of histopathological distribution of demyelination in the cortex (Geurts and Barkhof 2008). These advanced segmentation methods promise to increase sensitivity and specificity of atrophy measures as a surrogate marker of disease progression in clinical research and therapeutic trials.

Unfortunately, atrophy metrics are not yet in routine bedside clinical use owing to a variety 
of technical challenges and lack of consensus on a standardized technique (Azevedo and Pelletier 2016). The continued development of portable, fully automated methods of measurement show promise for future widespread use (Wang et al. 2016).

\section{SPINAL CORD IMAGING}

The spinal cord is a common and highly relevant site of involvement because of the MS disease processes; on conventional MRI imaging, cord lesions occur in up to $90 \%$ of MS patients once the disease is established (Bot et al. 2004a) and $30 \%-40 \%$ of patients at or before first symptoms (Okuda et al. 2011). Spinal cord lesions are part of the diagnostic criteria for dissemination in space in the International Panel guidelines (Polman et al. 2011). Similar pathologic processes affect the spinal cord as are seen in the brain: inflammatory demyelination, axonal/ neuronal loss, and atrophy. Imaging of the spinal cord is substantially more challenging than the brain as a result of the small size, motion artifacts, and inherently lower lesion contrast compared with normal cord tissue (Hittmair et al. 1996; McGowan 2000). Fortunately, ongoing technical innovations with both conventional and advanced MRI techniques, and increasing field strength, have allowed the deployment of more sensitive and reliable assessments of cord pathology in MS (Martin et al. 2016).

In the spinal cord, fast spin-echo T2-weighted, and STIR are most commonly used to identify lesions as part of routine care. Similar to the brain, conventional T2-weighted sequences reveal certain spatial patterns of inflammatory tissue abnormalities, typically localizing around venules in the posterior and lateral areas of the cord (Fig. 4). T2 hyperintense lesions are more common in the cervical versus the thoracic portion (Kearney et al. 2015) and correlate histologically with inflammatory demyelination (Bot et al. 2004b). Axonal and neuronal damage in the cord seems to occur largely independent of T2 lesions (Bergers et al. 2002), analogous to what has been described in the brain. Focal lesions are more characteristic of the RRMS stage, proceeding to become more confluent as the disease process progresses to SPMS. In primary progressive MS (PPMS), cord abnormalities more than brain lesions are a hallmark of disease (Thorpe et al. 1993) and tend to be diffuse compared to relapsing forms (Lycklama à Nijeholt et al. 1997).

Because of the high density of nonredundant (eloquent) axonal tissue in the cord, acute gadolinium-positive lesions tend to be more symptomatic compared with the brain (Thorpe et al. 1996) but occur at a lower frequency

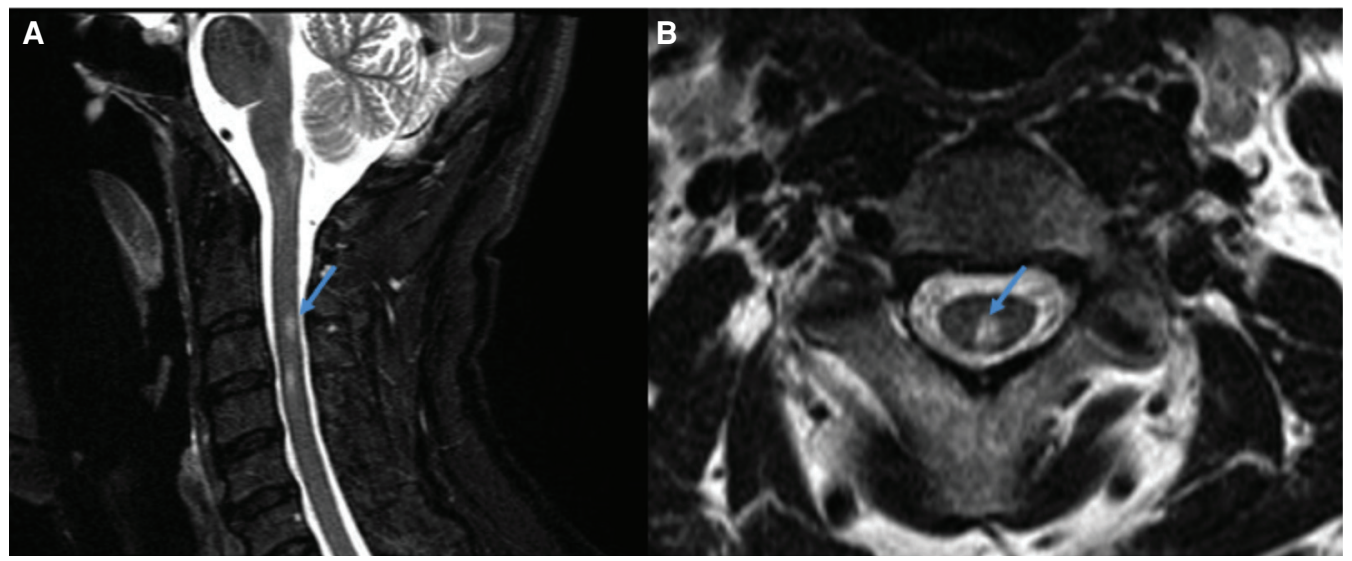

Figure 4. Typical multiple sclerosis (MS) lesions in the spinal cord. 3T magnetic resonance imaging (MRI) scans from a 46-year-old man with relapsing-remitting MS. (A) Short-tau inversion-recovery cervical spinal cord scan shows two hyperintense lesions at the C3 (arrow) and C3-C4 vertebral levels. (B) Axial fast spin-echo T2weighted scan through the superior (C3) lesion shows the dorsal midline location of the lesion (arrow). 
(Thorpe et al. 1993). Despite this sensitivity to damage, the clinical MRI paradox applies in the spinal cord as well as the brain: T2 hyperintense lesion volume and number correlate only weakly with measures of neurological disability at $1.5 \mathrm{~T}$ or $3 \mathrm{~T}$ (Stankiewicz et al. 2009). T1 hypointense MS lesions are rarely seen in the spinal cord.

High-resolution MRI with T1-weighted sequences can now efficiently and reliably assess spinal cord atrophy. Similar to the brain, cord atrophy correlates with measures of disability much more strongly than do metrics of T2 hyperintense lesions (Losseff et al. 1996; Horsfield et al. 2010). The most useful and frequently used measure of spinal cord atrophy is the mean cross-sectional area of the upper cervical cord (Losseff et al. 1996). Measurements of atrophy are typically most pronounced at this level, although a recent study using phase-sensitive inversion recovery has also shown that thoracic atrophy correlates with disability as well (Schlaeger et al. 2015). Studies using these types of advanced image acquisitions and new segmentation methods have shown a preference for GM versus WM loss in the spinal cord (analogous to what occurs in the brain); this GM tissue destruction correlates with disability and is much more pronounced in progressive versus relapsing forms (Schlaeger et al. 2014). Unfortunately, applying most of the above techniques on a single-subject basis lacks feasibility until further research is performed with large, welldesigned studies using standardized acquisition techniques and automated analysis methods (Martin et al. 2016).

Advanced quantitative spinal cord MRI techniques are emerging with the promise of providing even greater specificity and sensitivity to pathology (Zackowski et al. 2009). Such methods include quantitative T1 mapping, magnetization transfer imaging (MTI), and diffusion tensor imaging (DTI) (reviewed separately in this article). Although there are no spinal cord equivalents of the BHs seen in the brain, quantitative measures of $\mathrm{T} 1$ relaxometry show diffuse changes that correlate with axonal and myelin pathology (Mottershead et al. 2003). On postmortem histopathological correlation
Magnetic Resonance Imaging in Multiple Sclerosis

studies at 7T, these metrics correlate with axonal density as well as myelin content (Mottershead et al. 2003). Clinical disability is also significantly predicted by DTI (Agosta et al. 2007a) and MTI (Agosta et al. 2007b) measures in the cervical cord.

\section{SUSCEPTIBILITY-WEIGHTED IMAGING AND THE CENTRAL VEIN SIGN}

The paramagnetic properties of venous deoxygenated hemoglobin and other nonheme iron create local magnetic field inhomogeneities in the scanner magnet; these field disturbances can be exploited as a contrast signal with T2* weighted imaging. This forms the basis of both functional MRI as well as susceptibility-weighted imaging (SWI) in which venous contrasts are increased even further by the application of a phase attenuation pulse (Stüber et al. 2016). The sensitivity of T2* sequences increases with field strength, which also allows acquisition of high-resolution images of venous blood and iron distribution.

In MS, these sequences have recently been exploited to further explore the relationship between veins and inflammation. One key finding is the ability to commonly detect a central vein within a T2 hyperintense WM lesion (Fig. 5) (Tallantyre et al. 2009). This "central vein sign" is proposed to have high specificity for MS lesions compared with other diagnostic considerations, including small vessel disease (Tallantyre et al. 2011; Kilsdonk et al. 2014), migraine (Solomon et al. 2016), and other inflammatory conditions (Wuerfel et al. 2012; Absinta et al. 2016). Nikko Evangelou's group used 7T imaging to examine 29 patients with undiagnosed T2 hyperintensities and were able to predict with $100 \%$ positive and negative predictive value which ones later developed MS based on the percentage of lesions (greater or less than 45\%) with central vein signs (Mistry et al. 2013, 2015). Moreover, several investigators have found $\mathrm{T}^{*}$ signal changes (Absinta et al. 2015a; Kakeda et al. 2015) and an enlarged vein (Dal-Bianco et al. 2015) up to several months before the development of a colocalizing inflammatory lesion. The etiology of this 

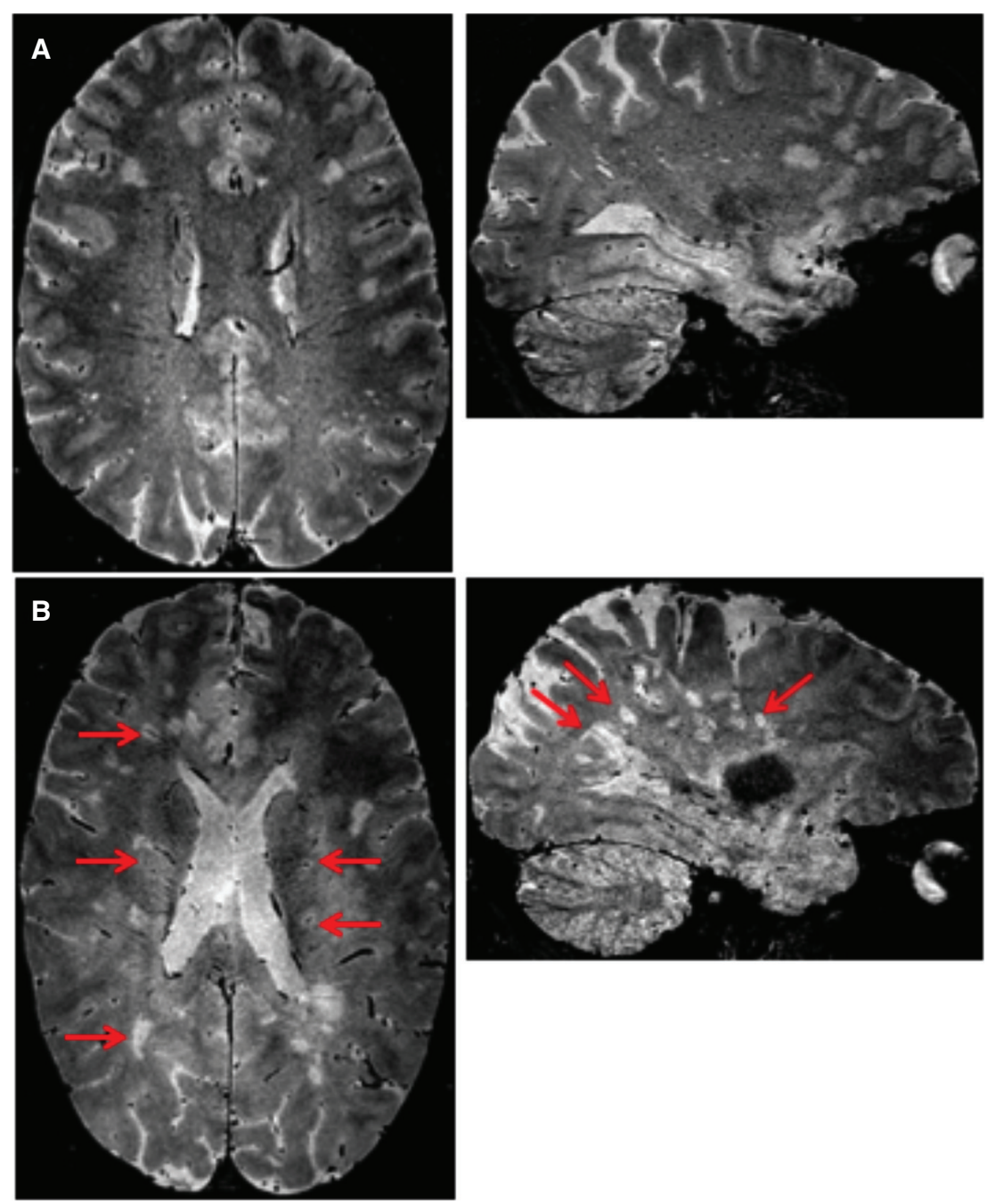

Figure 5. Central vein sign. T2* images at 3T. (A) White matter lesions in a patient with ischemic small vessel disease. The axial and sagittal views show small lesions in the deep white matter of the frontal lobes and in the subcortical region, which have no central veins. $(B)$ White matter lesions in a patient with relapsing-remitting multiple sclerosis, showing deep white matter and periventricular lesions with central veins (red arrows). Acquisition: 3T Achieva (Philips Healthcare, Best, The Netherlands), a 32-channel receive-only head coil, 3D T2*-weighted gradient-echo, with an echo planar imaging factor of 15 in the sagittal plane; the matrix was $448 \times 448 \times 336$ with a noninterpolated voxel size of $0.55 \times 0.55 \times 0.55 \mathrm{~mm}$. Parallel imaging factors of 2 in both phase encoding directions. In addition, the water-only excitation flip angle was 10 degrees, with an effective echo time of $29 \mathrm{~ms}$, repetition time of $54 \mathrm{~ms}$, and two signal averages similar to Sati et al. (2014). (Figure courtesy of Nikos Evangelou and colleagues.)

prominent vein within inflammatory lesions remains unclear although hypotheses include slower venous flow, postinflammatory scarring, or elevated concentrations of deoxyhemoglobin (Absinta et al. 2016). Larger studies among a wide variety of neuroimmunological diseases and other mimics of MS are required to deter- mine the true significance of this finding and its ultimate place in the diagnosis of MS.

As T2*-weighted imaging is sensitive to the paramagnetic signal from nonheme iron, it can also serve as a marker of iron deposition in the brain. Prior studies with spin-echo T2-weighted images noted diffuse hypointensity of the corti- 
cal and deep gray nuclei compared to healthy age-matched controls (Neema et al. 2007a; Stankiewicz et al. 2007) thought to be related to pathological iron deposits. The degree of T2 hypointensity in GM has shown correlations with measures of brain atrophy and clinical status, including physical disability and cognitive impairment (Neema et al. 2007a, 2009). A large number of recent studies using qualitative and quantitative measures of iron deposition using T2*-based methods have further confirmed these earlier findings, showing strong associations between the accumulation of deep GM iron and disease duration (Du et al. 2014; Khalil et al.2015), physical disability (Neema et al. 2009; Lebel et al. 2012; Walsh et al. 2014), and GM atrophy (Khalil et al. 2009; Zivadinov et al. 2012b). High levels of tissue iron may contribute to disease progression by oxidative stress, that is, reacting with hydrogen peroxide to create free radicals and lipid peroxidation followed by cell death (Stephenson et al. 2014). Ultimately, however, it is unclear whether abnormal iron accumulation is a primary contributor to pathogenesis or a result of neurodegeneration (epiphenomenon) in MS.

\section{PROTON MAGNETIC RESONANCE SPECTROSCOPY}

Proton MRS ( $\left.{ }^{1} \mathrm{H}-\mathrm{MRS}\right)$ complements conventional MRI by allowing in vivo measurements of the relative concentration of certain biochemical metabolites. Several important molecules have been reliably characterized using ${ }^{1} \mathrm{H}$-MRS, including $N$-acetylaspartate (NAA), creatine (Cr), choline (Cho), lactate (Lac), lipids, myoinositol (mI), GABA, and glutamate/glutamine (Sajja et al. 2009).

Metabolite concentrations deviating from normal are directly related to underlying biochemical changes, and ${ }^{1} \mathrm{H}-\mathrm{MRS}$ methods have yielded important pathophysiological insights into MS. NAA, for example, is highly concentrated in the normal brain, produced by mitochondria as a precursor for structures including myelin, and localized to axons, neuronal cell bodies, myelin, and oligodendrocytes, but not astrocytes or synapses (Nordengen et al. 2015). Reductions in NAA are thus commonly accepted to represent axonal/neuronal integrity and/or mitochondrial dysfunction. Numerous studies have consistently shown decreased NAA in both NAWM as well as normal-appearing GM (NAGM) in CIS (Wattjes et al. 2008), PPMS (Leary et al. 1999), and RRMS (Inglese et al. 2003; Tiberio et al. 2006; Kirov et al. 2013), as well as in the spinal cord (Sajja et al. 2009); these decreases correlate with axonal loss on histopathologic examination and represent neurodegeneration when persistent (Bitsch et al. 1999).

${ }^{1} \mathrm{H}$-MRS has additionally revealed widespread glutamate abnormalities in MS, a finding supportive of prior research suggesting cellular and metabolic dysfunction related to this neurotransmitter. There is evidence of elevated glutamate concentrations in both $\mathrm{T} 2$ hyperintense lesions as well as NAWM (Srinivasan et al. 2005); another group found that the degree of elevated glutamate concentrations in NAWM predicted the subsequent magnitude of brain atrophy, physical disability, and cognitive impairment, and declines in NAA in both GM and WM (Azevedo et al. 2014). Glutamate/glutamine concentrations in NAWM correlate with the MS severity scale, a measure of how rapidly disability accumulates normalized by time ( $\mathrm{Ti}$ sell et al. 2013). Last, ${ }^{1} \mathrm{H}$-MRS has been used clinically as a helpful adjunct diagnostic in cases of differentiating tumefactive/bizarre demyelinating lesions from neoplastic pathology (Saini et al. 2011; Lu et al. 2014).

Of note, the vast majority of studies using ${ }^{1} \mathrm{H}$-MRS feature relatively small sample sizes and are heterogeneous with regard to specific methodology and studied population. Until standardization of protocols and larger multicenter trials are performed, ${ }^{1} \mathrm{H}$-MRS remains relatively impractical for routine clinical use but promises ongoing valuable insights regarding molecular pathogenesis of MS disease processes and progression.

\section{MAGNETIZATION TRANSFER IMAGING}

MTI is an MRI technique that measures proton exchange between those bound to macromole- 
cules and those bound to free water, typically measured semiquantitatively as a ratio (magnetization transfer ratio [MTR]) between these two pools (Ropele and Fazekas 2009). Although MTI is affected by edema, axonal density, and inflammation, compared with conventional MRI, it shows a higher specificity for measuring myelin integrity, the overwhelming contribution to the macromolecule pool (Schmierer et al. 2004). This specificity for myelin injury has yielded insight into MS pathophysiology. Before the development of acute gadoliniumenhancing lesions, there are reductions in MTR (Filippi et al. 1998), followed by a precipitous drop corresponding to BBB breakdown, demyelination, and edema. Following resolution of gadolinium enhancement, the extent to which MTR recovers over the next 1-6 months depends on highly variable and patient-specific CNS repair mechanisms, which are incompletely understood (Patrikios et al. 2006). Rarely does the MTR recover completely to baseline; however, substantial reductions in MTR in acute lesions typically portend severe injury and progression to chronic BHs (Sahraian et al. 2010).

Despite certain advantages over conventional MRI, MTI generally remains a research tool rather than a clinical aid owing to challenges inherent in most advanced MRI techniques. That may be changing, as MTI's increased specificity for detection of myelin integrity has evolved into a useful adjunct outcome measure of remyelination and neuroprotection in clinical trials, most recently examining dimethyl fumarate (Arnold et al. 2014), natalizumab (Zivadinov et al. 2012a), and stem cell transplants (Brown et al. 2013). Standardized and quantified protocols are available, allowing multicenter MTI comparisons and, thus, this technique may gain traction as a primary method for quantifying remyelination and restorative agents in years to come (Harlow et al. 2015).

\section{DIFFUSION IMAGING}

Water shows random molecular (Brownian) motion that is constrained by various cellular structures in biological tissue. In WM tracts, water preferentially diffuses parallel to the di- rection of the axons (axial diffusivity), a physical principle that forms the basis for DTI and allows detailed microstructural mapping of the structural integrity of WM (Basser and Pierpaoli 1996). With the application of directional magnetic gradients in all three planes, diffusion imaging also captures water diffusion in directions perpendicular to WM tracts (radial diffusivity). Although axial diffusivity is felt to reflect axonal integrity, radial diffusivity captures aspects of myelination (Alexander et al. 2007; Budde et al. 2007). Fractional anisotropy (FA) is a common metric that captures the magnitude of diffusion directionality in a measured space; a low FA corresponds to unconstrained water diffusion, whereas a high FA signifies highly directional water diffusion. Nonspecific water diffusion changes are captured by a metric known as mean diffusivity (MD) (Pagani et al. 2007).

Both FA and MD show relatively strong correlations with myelin content, and to a lesser extent axonal count, on postmortem histological comparison (Schmierer et al. 2007). Similar to MTI, acute gadolinium enhancement in lesions may be preceded by an increase in MD several weeks earlier in NAWM (Rocca et al. 2000; Werring 2000). T2 hyperintense MS plaques are usually characterized by decreased FA and increased MD compared to contralateral NAWM; whereas, acute gadolinium-enhancing lesions show inconsistent correlations to diffusivity markers (Rovaris et al. 2005). Specificity in DTI is unfortunately compromised by other factors such as inflammation, edema, and gliosis, which also contribute to diffusivity changes. A novel, multitensor diffusion-based imaging method published by Wang and colleagues recently showed the potential to quantitatively differentiate coexisting edema from demyelination and axonal loss in individual MS lesions (Wang et al. 2015).

DTI-based tractography has emerged as a particularly attractive tool among diffusion metrics, providing insight into the mechanisms underlying the development of physical and cognitive impairment in both cross-sectional and longitudinal studies (Bodini et al. 2009; Ceccarelli et al. 2009; Van Hecke et al. 2010). Cognitive 
dysfunction is associated with decreased FA in the thalamus (Schoonheim et al. 2015) and corpus callosum (Dineen et al. 2009) as confirmed on a recent meta-analysis of 12 DTI studies (Welton et al. 2015). Motor impairment correlates strongly with diffusivity changes in the corticospinal tract (Lin et al. 2005, 2007). These studies suggest that tract-specific damage may explain variance in disability and offer the potential to bridge the clinical-MRI gap in predicting clinical outcome from imaging metrics. That being said, diffuse changes clearly are important as well; cognitive impairment worsened when WM tracts had more widespread damage (Hulst et al. 2013) and reduced efficiency of the brain at a network level correlated with physical disability (Shu et al. 2011).

Like other advanced MRI techniques (MRS and MTR), DTI offers the potential to improve specificity and pathological imaging correlations in MS. However, diffusion imaging has been included as an outcome measure in only a handful of small clinical trials with lukewarm results (Enzinger et al. 2015), and, for now, the technique remains primarily a research tool owing to difficulties in the interpretation of data and challenges with multicenter implementation (Pagani et al. 2010).

\section{NOVEL METHODS FOR DETECTION OF NEUROINFLAMMATION}

In contrast to gadolinium-enhancing lesionsan indirect measure of neuroinflammation via BBB breakdown-ultrasmall superparamagnetic particles of iron oxide (USPIO) are a direct measure of neuroinflammation. USPIO molecules are administered intravenously hours before imaging, during which time these particles are phagocytosed in the peripheral blood by monocytes before their infiltration into the CNS. The iron core acts to shorten T1 relaxation time and is consequently bright on T1-weighted images (Dousset et al. 1999). Coadministration of USPIO and gadolinium agents appears to increase detection of inflammatory lesions, and lesions that are dual-enhanced were characterized by a more severe evolution (Hagens et al. 2016). USPIO lesions have been detected in dis-
Magnetic Resonance Imaging in Multiple Sclerosis

ease states as early as CIS (Maarouf et al. 2015), and may ultimately yield novel pathophysiologic insights with regard to inflammatory mechanisms in MS-related macrophages/monocytes (Vellinga et al. 2008).

Another imaging modality that shows promise in identifying CNS neuroinflammation is positron emission tomography (PET). Radioactive ligands to the $18-\mathrm{kD}$ translocator protein (TSPO), a relatively specific marker for activated microglia, have shown increased binding and uptake in both lesions and NAWM in MS; there are additionally positive correlations with physical disability, disease duration, and brain atrophy (Hagens et al. 2016). Significant methodological variability, lack of large validated studies, and inherent patient pharmacodynamic heterogeneity limit the widespread clinical implementation of PET studies at present.

\section{CORTICAL LESIONS AND LEPTOMENINGEAL PATHOLOGY}

High field (3T) and ultrahigh field (e.g., 7T) MRIs have revealed significant insights into MS pathophysiology. One of the key findings is the increased ability to detect WM (Stankiewicz et al. 2011), cortical (Kilsdonk et al. 2016), deep central GM (Harrison et al. 2015a), and spinal cord (Dula et al. 2015) lesions, not typically apparent at lower field strengths. Regarding cortical lesions, it is now well accepted that widespread cortical demyelination, microgial activation, neuronal apotosis, and axonal loss is commonly present in the MS cortex (Peterson et al. 2001; Calabrese et al. 2015). Cortical demyelinating lesions are subdivided into three or four different subtypes based on location and histologic characteristics (Bø et al. 2003); they typically show significantly fewer activated immune cells and inflammatory infiltrates compared with lesions in the WM (Pirko et al. 2007). The relationship between WM and GM pathology remains unclear, with evidence to support at least partial interdependence of the two (Yousuf et al. 2016); this relationship remains an active area of research (Calabrese et al. 2015).

Cortical lesions are nearly absent on conventional MRI sequences at lower field strengths 
(e.g., 1.5T) using standard resolution. One study at $1.5 \mathrm{~T}$ using high-resolution 3D FLAIR showed only $5 \%$ of histologically confirmed cortical lesions, although this improved to $41 \%$ for mixed GM-WM (juxtacortical) and 71\% for purely WM lesions (Geurts et al. 2005b). Cortical lesions are difficult to detect at $1.5 \mathrm{~T}$ owing to intrinsically poor contrast resolution between GM lesions and NAGM, the small size of GM lesions, as well as partial-volume averaging effects at the border of GM tissue and sulcal CSF. Many studies have now clearly shown an improved cortical lesion detection rate with increasing magnetic field strengths. Lesion detection improves at $3 \mathrm{~T}$ compared with $1.5 \mathrm{~T}$ (Wattjes and Barkhof 2009; Simon et al. 2010) and at 7T compared to 3T (De Graaf et al. 2012; Filippi et al. 2014; Kilsdonk et al. 2016), although Kilsdonk and colleagues noted that even 7T still missed a significant number of subpial lesions. At 3T, high-resolution FLAIR and 3D T1-weighted images show some usage in detecting cortical lesions (Fig. 1) (Mike et al. 2011), particularly type 1 (GM-WM) and type II (purely intracortical). Advanced pulse sequences deployed at 3T, such as double inversion recovery (DIR) (Fartaria et al. 2015) and phase-sensitive inversion recovery (PSIR), show higher sensitivity to cortical lesion detection (Nelson et al. 2007). Regarding DIR, the high rate of interrater variability in cortical lesion analysis highlights the challenges for widespread deployment of this technique (Geurts et al. 2011; Seewann et al. 2012). Unfortunately, type III/IV lesions, the most common type of cortical lesions, remain elusive with 3T and lower field MRI (Mike et al. 2011). The use of 7T MRI has markedly boosted the sensitivity in the detection of cortical lesions in MS with the ability to reach $\sim 80 \%-90 \%$ of ground truth detection versus histology (Pitt et al. 2010).

Cortical lesions are common at the earliest stages of MS (Lucchinetti et al. 2011) and are present in both relapsing and progressive forms of the disease. Type III/IV lesions may be driven in part by focal meningeal inflammation as evidenced by histopathological correlation studies (Howell et al. 2011). A recent study at 7T showed early, superficial sulcal cortical pathology, which progressed to deeper cortical depths and spread to gyri in conjunction with disease progression (Mainero et al. 2015). T2-FLAIR postcontrast MRI has been recently used to detect focally enhancing leptomeningeal deposits in up to $25 \%$ of patients with relapsing disease and $40 \%$ of those with progressive subtypes (Absinta et al. 2015b); although this contrasts with a separate report using a different contrast protocol that identified leptomeningeal inflammation in $<1 \%$ of patients (Eisele et al. 2015). Further consideration of the role of gadolinium imaging to detect ongoing cortical leptomeningeal inflammation will require additional studies.

Cortical lesion accumulation is associated with GM atrophy, higher disease duration, and both cognitive impairment and physical disability at 1.5T (Calabrese et al. 2009, 2010; Roosendaal et al. 2009) and 3T (van de Pavert et al. 2015). A study at 7T, which allowed parsing of cortical layers, found a high burden of subpial lesions, in particular associated with severe physical disability (EDSS $>5$ ). Furthermore, leukocortical (GM-WM) lesions independently predicted cognitive impairment (Harrison et al. 2015b). Cortical lesion measures have been consistently found to correlate more strongly with disability compared with WM lesion load (Chard and Miller 2009).

\section{CONCLUSION}

MRI remains the most important paraclinical tool available to support the diagnosis and monitoring of MS. Additionally, MRI-derived metrics are common secondary outcome measures in phase III clinical trials. Conventional MRI sequences continue to provide high sensitivity in the diagnosis of MS, but lack specificity to identify precise pathology. Ultrahigh-field and advanced MRI techniques offer unique insight into the pathophysiology of MS along with increased specificity, but are limited in widespread adoption owing to lack of standardized protocols and large, well-controlled trials.

\section{ACKNOWLEDGMENTS}

The authors thank the following team members from Dr. Bakshi's laboratory for preparing Fig- 
ures 1-4: Renxin Chu, Sheena Dupuy, Fariha Khalid, Gloria Kim, Shahamat Tauhid, Subhash Tummalla, and Fawad Yousuf.

\section{REFERENCES}

Absinta M, Nair G, Sati P, Cortese ICM, Filippi M, Reich DS 2015a. Direct MRI detection of impending plaque development in multiple sclerosis. Neurol Neuroimmunol Neuroinflamm 2: e145.

Absinta M, Vuolo L, Rao A, Nair G, Sati P, Cortese ICM, Ohayon J, Fenton K, Reyes-Mantilla MI, Maric D, et al. 2015b. Gadolinium-based MRI characterization of leptomeningeal inflammation in multiple sclerosis. Neurology 85: $18-28$.

Absinta M, Sati P, Reich DS. 2016. Advanced MRI and staging of multiple sclerosis lesions. Nat Rev Neurol 12: 358368.

Agosta F, Absinta M, Sormani MP, Ghezzi A, Bertolotto A, Montanari E, Comi G, Filippi M. 2007a. In vivo assessment of cervical cord damage in MS patients: A longitudinal diffusion tensor MRI study. Brain 130: 2211-2219.

Agosta F, Pagani E, Caputo D, Filippi M. 2007b. Associations between cervical cord gray matter damage and disability in patients with multiple sclerosis. Arch Neurol 64: 13021305.

Alexander AL, Lee JE, Lazar M, Field AS. 2007. Diffusion tensor imaging of the brain. Neurotherapeutics 4: 316329.

Amato M, Portaccio E, Goretti B, Zipoli V, Battaglini M, Bartolozzi ML, Stromillo ML, Guidi L, Siracusa G, Sorbi S, et al. 2007. Association of neocortical volume changes with cognitive deterioration in relapsing-remitting multiple sclerosis. Arch Neurol 64: 1157-1161.

Arnold DL, Gold R, Kappos L, Bar-Or A, Giovannoni G, Selmaj K, Yang M, Zhang R, Stephan M, Sheikh SI, et al. 2014. Magnetization transfer ratio in the delayed-release dimethyl fumarate DEFINE study. J Neurol 261: 2429-2437.

Azevedo CJ, Pelletier D. 2016. Whole-brain atrophy: Ready for implementation into clinical decision-making in multiple sclerosis? Curr Opinion Neurol 29: 237-242.

Azevedo CJ, Kornak J, Chu P, Sampat M, Okuda DT, Cree BA, Nelson SJ, Hauser SL, Pelletier D. 2014. In vivo evidence of glutamate toxicity in multiple sclerosis. Ann Neurol 76: 269-278.

Azevedo CJ, Overton E, Khadka S, Buckley J, Liu S, Sampat M, Kantarci O, Lebrun Frenay C, Siva AA, Okuda DT, et al. 2015. Early CNS neurodegeneration in radiologically isolated syndrome. Neurol Neuroimmunol Neuroinflamm 2: e102.

Bagnato F, Jeffries N, Richert ND, Stone RD, Ohayon JM, McFarland HF, Frank JA. 2003. Evolution of T1 black holes in patients with multiple sclerosis imaged monthly for 4 years. Brain 126: 1782-1789.

Bakshi R, Dandamudi VSR, Neema M, De C, Bermel R 2005a. Measurement of brain and spinal cord atrophy by magnetic resonance imaging as a tool to monitor multiple sclerosis. J Neuroimaging 15: 30S-45S.
Bakshi R, Minagar A, Jaisani Z, Wolinsky JS. 2005b. Imaging of multiple sclerosis: Role in neurotherapeutics. NeuroRx 2: 277-303.

Bakshi R, Neema M, Healy BC, Liptak Z, Betensky R, Buckle GJ, Gauthier S, Stankiewicz J, Meier D, Egorova S, et al. 2008. Predicting clinical progression in multiple sclerosis with the magnetic resonance disease severity scale. Arch Neurol 65: 1449-1453.

Basser PJ, Pierpaoli C. 1996. Microstructural and physiological features of tissues elucidated by quantitative-diffusion-tensor MRI. J Magn Reson 213: 560-570.

Bergers E, Bot JCJ, De Groot CJ, Polman CH, Lycklama à Nijeholt GJ, Castelijns J, van der Valk P, Barkhof F. 2002. Axonal damage in the spinal cord of MS patients occurs largely independent of T2 MRI lesions. Neurology 59: 1766-1771.

Bermel RA, Bakshi R. 2006. The measurement and clinical relevance of brain atrophy in multiple sclerosis. Lancet Neurol 5: 158-170.

Bermel RA, Innus MD, Tjoa CW, Bakshi R. 2003. Selective caudate atrophy in multiple sclerosis: A 3D MRI parcellation study. Neuroreport 14: 335-339.

Bitsch A, Bruhn H, Vougioukas V, Stringaris A, Lassmann H, Frahm J, Brück W. 1999. Inflammatory CNS demyelination: Histopathologic correlation with in vivo quantitative proton MR spectroscopy. Am J Neuroradiol 20: 1619-1627.

Bitsch A, Kuhlmann T, Stadelmann C, Lassmann H, Lucchinetti C, Brück. 2001. A longitudinal MRI study of histopathologically defined hypointense multiple sclerosis lesions. Ann Neurol 49: 793-796.

Bø L, Vedeler CA, Nyland HI, Trapp BD, Mørk SJ. 2003. Subpial demyelination in the cerebral cortex of multiple sclerosis patients. J Neuropathol Exp Neurol 62: 723-732.

Bodini B, Khaleeli Z, Cercignani M, Miller DH, Thompson AJ, Ciccarelli O. 2009. Exploring the relationship between white matter and gray matter damage in early primary progressive multiple sclerosis: An in vivo study with TBSS and VBM. Hum Brain Mapp 30: 2852-2861.

Bot JCJ, Barkhof F, Polman CH, Lycklama à Nijeholt GJ, de Groot V, Bergers E, Ader HJ, Castelijns J. 2004a. Spinal cord abnormalities in recently diagnosed MS patients: Added value of spinal MRI examination. Neurology 62: 226-233.

Bot JCJ, Blezer ELA, Kamphorst W, Lycklama à Nijeholt GJ, Ader HJ, Castelijns JA, Ig KN, Bergers E, Ravid R, Polman C, et al. 2004b. The spinal cord in multiple sclerosis: Relationship of high-spatial-resolution quantitative MR imaging findings to histopathologic results. Radiology 233: 531-540.

Brex PA, Ciccarelli O, O’Riordan JI, Sailer M, Thompson AJ, Miller DH. 2002. A longitudinal study of abnormalities on MRI and disability from multiple sclerosis. $N$ Engl $J$ Med 346: 158-164.

Broome DR, Girguis MS, Baron PW, Cottrell AC, Kjellin I, Kirk GA. 2007. Gadodiamide-associated nephrogenic systemic fibrosis: Why radiologists should be concerned. Am J Roentgenol 188: 586-592.

Brown RA, Narayanan S, Arnold DL. 2013. Segmentation of magnetization transfer ratio lesions for longitudinal analysis of demyelination and remyelination in multiple sclerosis. Neuroimage 66: 103-109. 
Brück W, Bitsch A, Kolenda H, Brück Y, Stiefel M, Lassmann H. 1997. Inflammatory central nervous system demyelination: Correlation of magnetic resonance imaging findings with lesion pathology. Ann Neurol 42: 783-793.

Budde MD, Kim JH, Liang HF, Schmidt RE, Russell JH, Cross AH, Song SK. 2007. Toward accurate diagnosis of white matter pathology using diffusion tensor imaging. Magn Reson Med 57: 688-695.

Calabrese M, Agosta F, Rinaldi F, Mattisi I, Grossi P, Favaretto A, Atzori M, Bernardi V, Barachino L, Rinaldi L, et al. 2009. Cortical lesions and atrophy associated with cognitive impairment in relapsing-remitting multiple sclerosis. Arch Neurol 66: 1144-1150.

Calabrese M, Rocca MA, Atzori M, Mattisi I, Favaretto A, Perini P, Gallo P, Filippi M. 2010. A 3-year magnetic resonance imaging study of cortical lesions in relapseonset multiple sclerosis. Ann Neurol 67: 376-383.

Calabrese M, Magliozzi R, Ciccarelli O, Geurts JJG, Reynolds R, Martin R. 2015. Exploring the origins of grey matter damage in multiple sclerosis. Nat Rev Neurosci 16: 147158.

Ceccarelli A, Rocca MA, Valsasina P, Rodegher M, Pagani E, Falini A, Comi G, Filippi M. 2009. A multiparametric evaluation of regional brain damage in patients with primary progressive multiple sclerosis. Hum Brain Mapp 30: 3009-3019.

Chard D, Miller D. 2009. What you see depends on how you look: Gray matter lesions in multiple sclerosis. Neurology 73: 918-919.

Comi G, Filippi M, Wolinsky JS. 2001. European/Canadian multicenter, double-blind, randomized, placebo-controlled study of the effects of glatiramer acetate on magnetic resonance imaging-measured disease activity and burden in patients with relapsing multiple sclerosis. Ann Neurol 49: 290-297.

Cotton F, Weiner HL, Jolesz FA, Guttmann CRG. 2003. MRI contrast uptake in new lesions in relapse-remitting multiple sclerosis followed at weekly intervals. Neurology 60: 640-646.

Dal-Bianco A, Hametner S, Grabner G, Schernthaner M, Kronnerwetter C, Reitner A, Vass C, Kircher K, Auff E, Leutmezer F, et al. 2015. Veins in plaques of multiple sclerosis patients-A longitudinal magnetic resonance imaging study at 7 Tesla. Eur Radiol 25: 2913-2920.

Dalton CM, Miszkiel KA, Barker GJ, MacManus DG, Pepple TI, Panzara M, Yang M, Hulme A, O'Connor P, Miller DH. 2004. Effect of natalizumab on conversion of gadolinium enhancing lesions to T1 hypointense lesions in relapsing multiple sclerosis. J Neurol 251: 407-413.

Davis M, Auh S, Riva M, Richert ND, Frank JA, McFarland HF, Bagnato F. 2010. Ring and nodular multiple sclerosis lesions. Neurology 74: 851-856.

De Graaf WL, Zwanenburg JJM, Visser F, Wattjes MP, Pouwels PJW, Geurts JJG, Polman CH, Barkhof F, Luijten PR, Castelijns JA. 2012. Lesion detection at seven Tesla in multiple sclerosis using magnetisation prepared 3DFLAIR and 3D-DIR. Eur Radiol 22: 221-231.

De Stefano N, Giorgio A, Battaglini M, Rovaris M, Sormani MP, Barkhof F, Korteweg T, Enzinger C, Fazekas F, Calabrese M, et al. 2010. Assessing brain atrophy rates in a large population of untreated multiple sclerosis subtypes. Neurology 74: 1868-1876.
De Stefano N, Stromillo ML, Rossi F, Battaglini M, Giorgio A, Portaccio E, Hakiki B, Malentacchi G, Gasperini C, Santangelo M, et al. 2011. Improving the characterization of radiologically isolated syndrome suggestive of multiple sclerosis. PLoS ONE 6: e19452.

De Stefano N, Airas L, Grigoriadis N, Mattle HP, O’Riordan J, Oreja-Guevara C, Sellebjerg F, Stankoff B, Walczak A, Wiendl $\mathrm{H}$, et al. 2014. Clinical relevance of brain volume measures in multiple sclerosis. CNS Drugs 28: 147-156.

Dineen RA, Vilisaar J, Hlinka J, Bradshaw CM, Morgan PS, Constantinescu CS, Auer DP. 2009. Disconnection as a mechanism for cognitive dysfunction in multiple sclerosis. Brain 132: 239-249.

Dousset V, Ballarino L, Delalande C, Coussemacq M, Canioni P, Petry KG, Caillé JM. 1999. Comparison of ultrasmall particles of iron oxide (USPIO)-enhanced T2-weighted, conventional T2-weighted, and gadolinium-enhanced T1-weighted MR images in rats with experimental autoimmune encephalomyelitis. $\mathrm{Am} \mathrm{J} \mathrm{Neu-}$ roradiol 20: 223-227.

Du S, Sah SK, Zeng C, Wang J, Liu Y, Xiong H, Li Y. 2014. Iron deposition in the gray matter in patients with relapse-remitting multiple sclerosis: A longitudinal study using three-dimensional (3D)-enhanced $\mathrm{T} 2{ }^{*}$-weighted angiography (ESWAN). Eur J Radiol 84: 1325-1332.

Dula AN, Pawate S, Dortch RD, Barry RL, George-Durrett KM, Lyttle BD, Dethrage LM, Gore JC, Smith SA. 2015. Magnetic resonance imaging of the cervical spinal cord in multiple sclerosis at 7T. Mult Scler 22: 320-328.

Dupuy SL, Tauhid S, Kim G, Chu R, Tummala S, Hurwitz S, Bakshi R. 2015. MRI detection of hypointense brain lesions in patients with multiple sclerosis: T1 spin-echo vs. gradient-echo. Eur J Radiol 84: 1564-1568.

Eisele P, Griebe M, Szabo K, Wolf ME, Alonso A, Engelhardt B, Hennerici MG, Gass A. 2015. Investigation of leptomeningeal enhancement in MS: A postcontrast FLAIR MRI study. Neurology 84: 770-775.

Enzinger C, Barkhof F, Ciccarelli O, Filippi M, Kappos L, Rocca M, Ropele S, Rovira À, Schneider T, DDe Stefano $\mathrm{N}$, et al. 2015. Nonconventional MRI and microstructural cerebral changes in multiple sclerosis. Nat Rev Neurol 11: 676-686.

Fartaria MJ, Bonnier G, Roche A, Kober T, Meuli R, Rotzinger D, Frackowiak R, Schluep M, Du Pasquier R, Thiran JP, et al. 2015. Automated detection of white matter and cortical lesions in early stages of multiple sclerosis. J Magn Reson Imaging 43: 1445-1454.

Filippi M, Rocca MA. 2007. Conventional MRI in multiple sclerosis. J Neuroimaging 17: 3-9.

Filippi M, Rocca MA, Martino G, Horsfield MA, Comi G. 1998. Magnetization transfer changes in the normal appearing white matter precede the appearance of enhancing lesions in patients with multiple sclerosis. Ann Neurol 43: 809-814.

Filippi M, Rovaris M, Rocca MA, Sormani MP, Wolinsky JS, Comi G; Eurpoean/Canadian Glatiramer Acetate Study Group. 2001. Glatiramer acetate reduces the proportion of new MS lesions evolving into "black holes." Neurology 57: 731-733.

Filippi M, Evangelou N, Kangarlu A, Inglese M, Mainero C, Horsfield MA, Rocca MA. 2014. Ultra-high-field MR im- 
aging in multiple sclerosis. J Neurol Neurosurg Psychiatry 85: 60-66.

Filippi M, Rocca MA, Ciccarelli O, De Stefano N, Evangelou N, Kappos L, Rovira A, Sastre-Garriga J, Tintorè M, Frederiksen JL, et al. 2016. MRI criteria for the diagnosis of multiple sclerosis: MAGNIMS consensus guidelines. Lancet Neurol 15: 292-303.

Fischl B, Dale AM. 2000. Measuring the thickness of the human cerebral cortex from magnetic resonance images. Proc Natl Acad Sci 97: 11050-11055.

Fisher E, Chang A, Fox RJ, Tkach JA, Svarovsky T, Nakamura K, Rudick RA, Trapp BD. 2007. Imaging correlates of axonal swelling in chronic multiple sclerosis brains. Ann Neurol 62: 219-228.

Fisher E, Lee JC, Nakamura K, Rudick RA. 2008. Gray matter atrophy in multiple sclerosis: A longitudinal study. Ann Neurol 64: 255-265.

Gaitann MI, Shea CD, Evangelou IE, Stone RD, Fenton KM, Bielekova B, Massacesi L, Reich DS. 2011. Evolution of the blood-brain barrier in newly forming multiple sclerosis lesions. Ann Neurol 70: 22-29.

Geurts JJ, Barkhof F. 2008. Grey matter pathology in multiple sclerosis. Lancet Neurol 7: 841-851.

Geurts JJ, Pouwels PJ, Uitdehaag BM, Polman CH, Castelijns JA, Barkhof F. 2005a. Intracortical lesions in multiple sclerosis: Improved detection with 3D double inversionrecovery MR imaging. Radiology 236: 254-260.

Geurts JJG, Bö L, Pouwels PJW, Castelijns JA, Polman CH, Barkhof F. 2005b. Cortical lesions in multiple sclerosis: Combined postmortem MR imaging and histopathology. Am J Neuroradiol 26: 572-577.

Geurts JJG, Roosendaal SD, Calabrese M, Ciccarelli O, Agosta F, Chard DT, Gass A, Huerga E, Moraal B, Pareto D, et al. 2011. Consensus recommendations for MS cortical lesion scoring using double inversion recovery MRI. Neurology 76: 418-424.

Grassiot B, Desgranges B, Eustache F, Defer G. 2009. Quantification and clinical relevance of brain atrophy in multiple sclerosis: A review. J Neurol 256: 1397-1412.

Hagens M, Van Berckel B, Barkhof F. 2016. Novel MRI and PET markers of neuroinflammation in multiple sclerosis. Curr Opin Neuro 29: 1-8.

Harlow DE, Honce JM, Miravalle AA. 2015. Remyelination therapy in multiple sclerosis. Front Neurol 6: 1-13.

Harrison DM, Oh J, Roy S, Wood ET, Whetstone A, Seigo M, Jones CK, Pham D, van Zijl P, Reich DS, et al. 2015a. Thalamic lesions in multiple sclerosis by 7T MRI: Clinical implications and relationship to cortical pathology. Mult Scler J 21: 1139-1150.

Harrison DM, Roy S, Oh J, Izbudak I, Pham D, Courtney S, Caffo B, Jones CK, van Zijl P, Calabresi PA. 2015b. Association of cortical lesion burden on 7-T magnetic resonance imaging with cognition and disability in multiple sclerosis. JAMA Neurol 72: 1004-1012.

Henry RG, Shieh M, Okuda DT, Evangelista A, Gorno-Tempini ML, Pelletier D. 2008. Regional grey matter atrophy in clinically isolated syndromes at presentation. J Neurol Neurosurg Psychiatry 79: 1236-1244.

Hittmair K, Mallek R, Prayer D, Schindler EG, Kollegger H. 1996. Spinal cord lesions in patients with multiple scle- rosis: Comparison of MR pulse sequences. AJNR Am J Neuroradiol 17: 1555-1565.

Horsfield MA, Sala S, Neema M, Absinta M, Bakshi A, Sormani MP, Rocca MA, Bakshi R, Filippi M. 2010. Rapid semi-automatic segmentation of the spinal cord from magnetic resonance images: Application in multiple sclerosis. Neuroimage 50: 446-455.

Houtchens MK, Benedict RHB, Killiany R, Sharma J, Jaisani Z, Singh B, Weinstock-Guttman B, Guttmann CRG, Bakshi R. 2007. Thalamic atrophy and cognition in multiple sclerosis. Neurology 69: 1213-1223.

Howell OW, Reeves CA, Nicholas R, Carassiti D, Radotra B, Gentleman SM, Serafini B, Aloisi F, Roncaroli F, Magliozzi R, et al. 2011. Meningeal inflammation is widespread and linked to cortical pathology in multiple sclerosis. Brain 134: 2755-2771.

Hulst HE, Steenwijk MD, Versteeg A, Pouwels PJW, Vrenken H, Uitdehaag BMJ, Polman CH, Geurts JJG, Barkhof F. 2013. Cognitive impairment in MS: Impact of white matter integrity, gray matter volume, and lesions. Neurology 80: 1025-1032.

Inglese M, Li BSY, Rusinek H, Babb JS, Grossman RI, Gonen O. 2003. Diffusely elevated cerebral choline and creatine in relapsing-remitting multiple sclerosis. Magn Reson Med 50: 190-195.

Kakeda S, Futatsuya K, Ide S, Watanabe K, Miyata M, Moriya J, Ogasawara A, Sato T, Narimatsu H, Okada K, et al. 2015. Improved detection of cortical gray matter involvement in multiple sclerosis with quantitative susceptibility mapping. Acad Radiol 22: 1427-1432.

Kappos L, Moeri D, Radue EW, Schoetzau A, Schweikert K, Barkhof F, Miller D, Guttman CRG, Weiner HL, Gasperini C, et al. 1999. Predictive value of gadolinium-enhanced magnetic resonance imaging for relapse rate and changes in disability or impairment in multiple sclerosis: A meta-analysis. Lancet 353: 964-969.

Kearney H, Miller DH, Ciccarelli O. 2015. Spinal cord MRI in multiple sclerosis-diagnostic, prognostic and clinical value. Nat Rev Neurol 11: 327-338.

Khalil M, Enzinger C, Langkammer C, Tscherner M, Wallner-Blazek M, Jehna M, Ropele S, Fuchs S, Fazekas F. 2009. Quantitative assessment of brain iron by $R_{2}{ }^{*}$ relaxometry in patients with clinically isolated syndrome and relapsing-remitting multiple sclerosis. Mult Scler 15: 1048-1054.

Khalil M, Langkammer C, Pichler A, Pinter D, Gattringer T, Bachmaier G, Ropele S, Fuchs S, Enzinger C, Fazekas F. 2015. Dynamics of brain iron levels in multiple sclerosis: A longitudinal 3T MRI study. Neurology 84: 2396-2402.

Kilsdonk ID, Wattjes MP, Lopez-Soriano A, Kuijer JPA, De Jong MC, De Graaf WL, Conijn MMA, Polman CH, Luijten PR, Geurts JJG, et al. 2014. Improved differentiation between MS and vascular brain lesions using FLAIR* at 7 Tesla. Eur Radiol 24: 841-849.

Kilsdonk ID, Jonkman LE, Klaver R, van Veluw SJ, Zwanenburg JJM, Kuijer JPA, Pouwels PJW, Twisk JWR, Wattjes MP, Luijten PR, et al. 2016. Increased cortical grey matter lesion detection in multiple sclerosis with 7 T MRI: A post-mortem verification study. Brain 139: 1472-1481.

Kirov II, Tal A, Babb JS, Herbert J, Gonen O. 2013. Serial proton MR spectroscopy of gray and white matter in relapsing-remitting MS. Neurology 80: 39-46. 
C.C. Hemond and R. Bakshi

Labiano-Fontcuberta A, Mato-Abad V, Álvarez-Linera J, Hernández-Tamames JA, Martínez-Ginés ML, Aladro Y, Ayuso L, Domingo-Santos Á, Benito-León J. 2016. Gray matter involvement in radiologically isolated syndrome. Medicine (Baltimore) 95: e3208.

Leary SM, Davie CA, Parker GJ, Stevenson VL, Wang L, Barker GJ, Miller DH, Thompson AJ. 1999. ${ }^{1} \mathrm{H}$ magnetic resonance spectroscopy of normal appearing white matter in primary progressive multiple sclerosis. J Neurol 246: 1023-1026.

Lebel RM, Eissa A, Seres P, Blevins G, Wilman AH. 2012. Quantitative high-field imaging of sub-cortical gray matter in multiple sclerosis. Mult Scler 18: 433-441.

Lin X, Tench CR, Morgan PS, Niepel G, Constantinescu CS. 2005. "Importance sampling" in MS: Use of diffusion tensor tractography to quantify pathology related to specific impairment. J Neurol Sci 237: 13-19.

Lin F, Yu C, Jiang T, Li K, Chan P. 2007. Diffusion tensor tractography-based group mapping of the pyramidal tract in relapsing-remitting multiple sclerosis patients. $A m J$ Neuroradiol 28: 278-282.

Losseff NA, Webb SL, O'Riordan JI, Page R, Wang L, Barker GJ, Tofts PS, McDonald WI, Miller DH, Thompson AJ. 1996. Spinal cord atrophy and disability in multiple sclerosis. A new reproducible and sensitive MRI method with potential to monitor disease progression. Brain 119: 701708 .

Lu SS, Kim SJ, Kim HS, Choi CG, Lim YM, Kim EJ, Kim DY, Cho SH. 2014. Utility of proton MR spectroscopy for differentiating typical and atypical primary central nervous system lymphomas from tumefactive demyelinating lesions. Am J Neuroradiol 35: 270-277.

Lucchinetti CFC, Popescu BFGB, Bunyan RF, Moll NM, Roemer SF, Lassmann H, Brück W, Parisi JE, Scheithauer BW, Giannini C, et al. 2011. Inflammatory cortical demyelination in early multiple sclerosis. N Engl J Med 365: 2188-2197.

Lycklama à Nijeholt GJ, Barkhof F, Scheltens P, Castelijns JA, Adèr H, Van Waesberghe JH, Polman C, Jongen SJH, Valk J. 1997. MR of the spinal cord in multiple sclerosis: Relation to clinical subtype and disability. Am J Neuroradiol 18: 1041-1048.

Maarouf A, Ferré JC, Zaaraoui W, Le Troter A, Bannier E, Berry I, Guye M, Pierot L, Barillot C, Pelletier J, et al. 2015. Ultra-small superparamagnetic iron oxide enhancement is associated with higher loss of brain tissue structure in clinically isolated syndrome. Mult Scler 22: 1032-1039.

Mahad DH, Trapp BD, Lassmann H. 2015. Pathological mechanisms in progressive multiple sclerosis. Lancet Neurol 14: 183-193.

Mainero C, Louapre C, Govindarajan ST, Gianni C, Scott Nielsen A, Cohen-Adad J, Sloane J, Kinkel RP. 2015. A gradient in cortical pathology in multiple sclerosis by in vivo quantitative $7 \mathrm{~T}$ imaging. Brain 138: 932-945.

Martin AR, Aleksanderek I, Cohen-Adad J, Tarmohamed Z, Tetreault L, Smith N, Cadotte DW, Crawley A, Ginsberg H, Mikulis DJ, et al. 2016. Translating state-of-the-art spinal cord MRI techniques to clinical use: A systematic review of clinical studies utilizing DTI, MT, MWF, MRS, and fMRI. NeuroImage Clin 10: 192-238.
Marziniak M, Meuth S. 2014. Current perspectives on interferon $\beta-1 \mathrm{~b}$ for the treatment of multiple sclerosis. $A d v$ Ther 31: 915-931.

Masdeu JC, Moreira J, Trasi S, Visintainer P, Cavaliere R, Grundman M. 1996. The open ring. A new imaging sign in demyelinating disease. J Neuroimaging 6: 104-107.

Masdeu JC, Quinto C, Olivera C, Tenner M, Leslie D, Visintainer P. 2000. Open-ring imaging sign: Highly specific for atypical brain demyelination. Neurology 54: 14271433.

McDonald I, Compston A, Edan G, Goodkin D, Hartung H-P, Lublin FD, McFarland HF, Paty DW, Polman CH, Reingold SC, et al. 2001. Recommended diagnostic criteria for multiple sclerosis: Guidelines from the International Panel on the Diagnosis of Multiple Sclerosis. Ann Neurol 59: 11456302.

McFarland HF. 2009. Examination of the role of magnetic resonance imaging in multiple sclerosis: A problem-orientated approach. Ann Indian Acad Neurol 12: 254-263.

McGowan JC. 2000. Technical issues for MRI examination of the spinal cord. J Neurol Sci 172: S27-S31.

Meier DS, Weiner HL, Guttmann CRG. 2007. Time-series modeling of multiple sclerosis disease activity: A promising window on disease progression and repair potential? Neurotherapeutics 4: 485-498.

Mike AA, Glanz BI, Hildenbrand P, Meier D, Bolden K, Liguori M, Dell'Oglio E, Healy BC, Bakshi R, Guttmann CRG. 2011. Identification and clinical impact of multiple sclerosis cortical lesions as assessed by routine $3 \mathrm{~T}$ MR imaging. AJNR Am J Neuroradiol 32: 515-521.

Minagar A, Alexander JS. 2003. Blood-brain barrier disruption in multiple sclerosis. Mult Scler 9: 540-549.

Minneboo A, Uitdehaag BMJ, Ader HJ, Barkhof F, Polman $\mathrm{CH}$, Castelijns JA. 2005. Patterns of enhancing lesion evolution in multiple sclerosis are uniform within patients. Neurology 65: 56-61.

Mistry N, Dixon J, Tallantyre E, Tench C, Abdel-Fahim R, Jaspan T, Morgan PS, Morris P, Evangelou N. 2013. Central veins in brain lesions visualized with high-field magnetic resonance imaging: A pathologically specific diagnostic biomarker for inflammatory demyelination in the brain. JAMA Neurol 70: 623-628.

Mistry N, Abdel-Fahim R, Samaraweera A, Mougin O, Tallantyre E, Tench C, Jaspan T, Morris P, Morgan PS, Evangelou N. 2015. Imaging central veins in brain lesions with 3-T T2* -weighted magnetic resonance imaging differentiates multiple sclerosis from microangiopathic brain lesions. Mult Scler 22: 1289-1296.

Molyneux PD, Filippi M, Barkhof F, Gasperini C, Yousry TA, Truyen L, Lai HM, Rocca MA, Moseley IF, Miller DH. 1998. Correlations between monthly enhanced MRI lesion rate and changes in T2 lesion volume in multiple sclerosis. Ann Neurol 43: 332-339.

Molyneux PD, Brex PA, Fogg C, Lewis S, Middleditch C, Barkhof F, Sormani MP, Filippi M, Miller DH. 2000. The precision of T1 hypointense lesion volume quantification in multiple sclerosis treatment trials: A multicenter study. Mult Scler 6: 237-240.

Mottershead JP, Schmierer K, Clemence M, Thornton JS, Scaravilli F, Barker GJ, Tofts PS, Newcombe J, Cuzner ML, Ordidge RJ, et al. 2003. High field MRI correlates of myelin content and axonal density in multiple sclero- 
sis: A post-mortem study of the spinal cord. J Neurol 250: 1293-1301.

Nakamura K, Brown RA, Narayanan S, Collins DL, Arnold DL. 2015. Diurnal fluctuations in brain volume: Statistical analyses of MRI from large populations. Neuroimage 118: 126-132.

Neema M, Stankiewicz J, Arora A, Dandamudi VSR, Batt CE, Guss ZD, Al-Sabbagh A, Bakshi R. 2007a. T1- and T2-based MRI measures of diffuse gray matter and white matter damage in patients with multiple sclerosis. $J \mathrm{Neu}$ roimaging 17: 16S-21S.

Neema M, Stankiewicz J, Arora A, Guss ZD, Bakshi R 2007b. MRI in multiple sclerosis: What's inside the toolbox? Neurotherapeutics 4: 602-617.

Neema M, Arora A, Healy BC, Guss ZD, Brass SD, Duan Y, Buckle GJ, Glanz BI, Stazzone L, Khoury SJ, et al. 2009. Deep gray matter involvement on brain MRI scans is associated with clinical progression in multiple sclerosis. J Neuroimaging 19: 3-8.

Nelson F, Poonawalla AH, Hou P, Huang F, Wolinsky JS, Narayana PA. 2007. Improved identification of intracortical lesions in multiple sclerosis with phase-sensitive inversion recovery in combination with fast double inversion recovery MR imaging. Am J Neuroradiol 28: 16451649.

Nicholas J, Morgan-Followell B, Pitt D, Racke MK, Boster A. 2012. New and emerging disease-modifying therapies for relapsing-remitting multiple sclerosis: What is new and what is to come. J Cent Nerv Syst Dis 4: 81-103.

Nordengen K, Heuser C, Rinholm JE, Matalon R, Gundersen V. 2015. Localisation of $N$-acetylaspartate in oligodendrocytes/myelin. Brain Struct Funct 220: 899-917.

Okuda DT, Mowry EM, Cree BAC, Crabtree EC, Goodin DS, Waubant E, Pelletier D. 2011. Asymptomatic spinal cord lesions predict disease progression in radiologically isolated syndrome. Neurology 76: 686-692.

Oommen VV, Tauhid S, Healy BC, Chua AS, Malik MT, Diaz-Cruz C, Dupuy SL, Weiner HL, Chitnis T, Bakshi R. 2016. The effect of fingolimod on conversion of acute gadolinium-enhancing lesions to chronic T1 hypointensities in multiple sclerosis. J Neuroimaging 26: 184-187.

Pagani E, Bammer R, Horsfield M, Rovaris M, Gass A, Ciccarelli O, Filippi M. 2007. Diffusion MR imaging in multiple sclerosis: Technical aspects and challenges. AJNR Am J Neuroradiol 28: 411-420.

Pagani E, Hirsch JG, Pouwels PJW, Horsfield MA, Perego E, Gass A, Roosendaal SD, Barkhof F, Agosta F, Rovaris M, et al. 2010. Intercenter differences in diffusion tensor MRI acquisition. J Magn Reson Imaging 31: 1458-1468.

Patrikios P, Stadelmann C, Kutzelnigg A, Rauschka H, Schmidbauer M, Laursen H, Sorensen PS, Brück W, Lucchinetti C, Lassmann H. 2006. Remyelination is extensive in a subset of multiple sclerosis patients. Brain 129: 31653172.

Peterson JW, Bo L, Mork S, Chang A, Trapp BD. 2001. Transected neurites, apoptotic neurons, and reduced inflammation in cortical multiple sclerosis lesions. Ann Neurol 50: 389-400.

Pirko I, Lucchinetti CF, Sriram S, Bakshi R. 2007. Gray matter involvement in multiple sclerosis. Neurology 68: 634642.
Magnetic Resonance Imaging in Multiple Sclerosis

Pitt D, Boster A, Pei W, Wohleb E, Jasne A, Zachariah CR, Rammohan K, Knopp M V, Schmalbrock P. 2010. Imaging cortical lesions in multiple sclerosis with ultra-highfield magnetic resonance imaging. Arch Neurol 67: 812818.

Polman CH, Reingold SC, Banwell B, Clanet M, Cohen JA, Filippi M, Fujihara K, Havrdova E, Hutchinson M, Kappos L, et al. 2011. Diagnostic criteria for multiple sclerosis: 2010 Revisions to the McDonald criteria. Ann Neurol 69: 292-302.

Radue EW, Bendfeldt K, Mueller-Lenke N, Magon S, Sprenger T. 2013. Brain atrophy: An in-vivo measure of disease activity in multiple sclerosis. Swiss Med Wkly 143: $1-11$.

Radue EW, Barkhof F, Kappos L, Sprenger T, Häring DA, De Vera A, Von Rosenstiel P, Bright JR, Francis G, Cohen JA. 2015. Correlation between brain volume loss and clinical and MRI outcomes in multiple sclerosis. Neurology 84: 784-793.

Rocca MA, Cercignani M, Iannucci G, Comi G, Filippi M. 2000. Weekly diffusion-weighted imaging of normal-appearing white matter in MS. Neurology 55: 882-884.

Rojas JI, Patrucco L, Míguez J, Besada C, Cristiano E. 2015. Brain atrophy in radiologically isolated syndromes. J Neuroimaging 25: $68-71$.

Roosendaal SD, Moraal B, Pouwels PJW, Vrenken H, Castelijns JA, Barkhof F, Geurts JJG. 2009. Accumulation of cortical lesions in MS: Relation with cognitive impairment. Mult Scler 15: 708-714.

Ropele S, Fazekas F. 2009. Magnetization transfer MR imaging in multiple sclerosis. Neuroimaging Clin N Am 19: 27-36.

Rovaris M, Gass A, Bammer R, Hickman SJ, Ciccarelli O, Miller DH, Filippi M. 2005. Diffusion MRI in multiple sclerosis. Neurology 65: 1526-1532.

Rovira A, Alonso J, Cucurella G, Nos C, Tintoré M, Pedraza S, Rio J, Montalban X. 1999. Evolution of multiple sclerosis lesions on serial contrast-enhanced T1-weighted and magnetization-transfer MR images. AJNR Am J Neuroradiol 20: 1939-1945.

Rovira A, Auger C, Alonso J. 2013. Magnetic resonance monitoring of lesion evolution in multiple sclerosis Ther Adv Neurol Disord 6: 298-310.

Sahraian MA, Radue EW, Haller S, Kappos L. 2010. Black holes in multiple sclerosis: Definition, evolution, and clinical correlations. Acta Neurol Scand 122: 1-8.

Saini J, Chatterjee S, Thomas B, Kesavadas C. 2011. Conventional and advanced magnetic resonance imaging in tumefactive demyelination. Acta Radiol 52: 1159-1168.

Sajja BR, Wolinsky JS, Narayana PA. 2009. Proton magnetic resonance spectroscopy in multiple sclerosis. Neuroimaging Clin N Am 19: 45-58.

Sanfilipo MP, Benedict RHB, Weinstock-Guttman B, Bakshi R. 2006. Gray and white matter brain atrophy and neuropsychological impairment in multiple sclerosis. Neurology 66: 685-692.

Sati P, Thomasson D, Li N, Pham D, Biassou N, Reich D, Butman J. 2014. Rapid, high-resolution, whole-brain, susceptibility-based MRI of multiple sclerosis. Mult Scler 20: 1464-1470. 
Schlaeger R, Papinutto N, Panara V, Bevan C, Lobach I V, Bucci M, Caverzasi E, Gelfand JM, Green AJ, Jordan KM, et al. 2014. Spinal cord gray matter atrophy correlates with multiple sclerosis disability. Ann Neurol 76: 568-580.

Schlaeger R, Papinutto N, Zhu AH, Lobach IV, Bevan CJ, Bucci M, Castellano A, Gelfand JM, Graves JS, Green AJ, et al. 2015. Association between thoracic spinal cord gray matter atrophy and disability in multiple sclerosis. JAMA Neurol 72: 897-904.

Schmierer K, Scaravilli F, Altmann DR, Barker GJ, Miller DH. 2004. Magnetization transfer ratio and myelin in postmortem multiple sclerosis brain. Ann Neurol 56: 407-415.

Schmierer K, Wheeler-Kingshott CAM, Boulby PA, Scaravilli F, Altmann DR, Barker GJ, Tofts PS, Miller DH. 2007. Diffusion tensor imaging of post mortem multiple sclerosis brain. Neuroimage 35: 467-477.

Schoonheim MM, Hulst HE, Brandt R, Strik M, Wink M, Uitehaag B, Barkhof F, Geurts JJ. 2015. Thalamus structure and function determines severity of cognitive impairment in multiple sclerosis. Neurology 84: 776-783.

Seewann A, Kooi EJ, Roosendaal SD, Pouwels PJW, Wattjes MP, Van Der Valk P, Barkhof F, Polman CH, Geurts JJG 2012. Postmortem verification of MS cortical lesion detection with 3D DIR. Neurology 78: 302-308.

Shu N, Liu Y, Li K, Duan Y, Wang J, Yu C, Dong H, Ye J, He Y. 2011. Diffusion tensor tractography reveals disrupted topological efficiency in white matter structural networks in multiple sclerosis. Cereb Cortex 21: 2565-2577.

Simon B, Schmidt S, Lukas C, Gieseke J, Träber F, Knol DL, Willinek WA, Geurts JJG, Schild HH, Barkhof F, et al 2010. Improved in vivo detection of cortical lesions in multiple sclerosis using double inversion recovery $\mathrm{MR}$ imaging at 3 Tesla. Eur Radiol 20: 1675-1683.

Sinnecker T, Kuchling J, Dusek P, Dörr J, Niendorf T, Paul F, Wuerfel J. 2015. Ultrahigh field MRI in clinical neuroimmunology: A potential contribution to improved diagnostics and personalised disease management. EPMA J 6: 16.

Solomon AJ, Schindler MK, Howard DB, Watts R, Sati P, Nickerson JP, Reich DS. 2016. "Central vessel sign" on 3T FLAIR* MRI for the differentiation of multiple sclerosis from migraine. Ann Clin Transl Neurol 3: 82-87.

Srinivasan R, Sailasuta N, Hurd R, Nelson S, Pelletier D. 2005. Evidence of elevated glutamate in multiple sclerosis using magnetic resonance spectroscopy at 3 T. Brain 128: 1016-1025.

Stankiewicz J, Panter SS, Neema M, Arora A, Batt CE, Bakshi R. 2007. Iron in chronic brain disorders: Imaging and neurotherapeutic implications. Neurotherapeutics 4: 371-386.

Stankiewicz JM, Neema M, Alsop DC, Healy BC, Arora A, Buckle GJ, Chitnis T, Guttmann CRG, Hackney D, Bakshi R. 2009. Spinal cord lesions and clinical status in multiple sclerosis: A 1.5 T and 3 T MRI study. J Neurol Sci 279: 99105.

Stankiewicz JM, Glanz BI, Healy BC, Arora A, Neema M, Benedict RHB, Guss ZD, Tauhid S, Buckle GJ, Houtchens MK, et al. 2011. Brain MRI lesion load at $1.5 \mathrm{~T}$ and $3 \mathrm{~T}$ vs. clinical status in multiple sclerosis. J Neuroimaging 21: 115.
Steckova T, Hlustik P, Sladkova V, Odstrcil F, Mares J, Kanovsky P. 2014. Thalamic atrophy and cognitive impairment in clinically isolated syndrome and multiple sclerosis. J Neurol Sci 342: 62-68.

Stephenson E, Nathoo N, Mahjoub Y, Dunn JF, Yong VW. 2014. Iron in multiple sclerosis: Roles in neurodegeneration and repair. Nat Rev Neurol 10: 459-468.

Stojanov D, Aracki-Trenkic A, Benedeto-Stojanov D. 2016. Gadolinium deposition within the dentate nucleus and globus pallidus after repeated administrations of gadolinium-based contrast agents-Current status. Neuroradiology 58: 433-441.

Stüber C, Pitt D, Wang Y. 2016. Iron in multiple sclerosis and its noninvasive imaging with quantitative susceptibility mapping. Int J Mol Sci 17: 100.

Tallantyre EC, Morgan PS, Dixon JE, Al-Radaideh A, Brookes MJ, Evangelou N, Morris PG. 2009. A comparison of 3T and 7T in the detection of small parenchymal veins within MS lesions. Invest Radiol 44: 491-494.

Tallantyre EC, Dixon JE, Donaldson I, Owens T, Morgan PS, Morris PG, Evangelou N. 2011. Ultra-high-field imaging distinguishes MS lesions from asymptomatic white matter lesions. Neurology 76: 534-539.

Tauhid S, Neema M, Healy BC, Weiner HL, Bakshi R. 2014. MRI phenotypes based on cerebral lesions and atrophy in patients with multiple sclerosis. J Neurol Sci 346: 250254.

Tedeschi G, Dinacci D, Comerci M, Lavorgna L, Savettieri G, Quattrone A, Livrea P, Patti F, Morra VB, Servillo G, et al. 2009. Brain atrophy evolution and lesion load accrual in multiple sclerosis: A 2-year follow-up study. Mult Scler 15: 204-211.

Thaler C, Faizy T, Sedlacik J, Holst B, Stellmann J, Young KL, Heesen C, Fiehler J, Siemonsen S. 2015. T1- Thresholds in black holes increase clinical-radiological correlation in multiple sclerosis patients. PLOS ONE 10: e0144693.

Thorpe JW, Kidd D, Kendall BE, Tofts PS, Barker GJ, Thompson AJ, Macmanus DG, McDonald WI, Miller DH. 1993. Spinal cord MRI using multi-array coils and fast spin echo. 1: Technical aspects and findings in healthy adults. Neurology 43: 2625-2631.

Thorpe JW, Kidd D, Moseley IF, Kenndall BE, Thompson AJ, MacManus DG, McDonald WI, Miller DH. 1996 Serial gadolinium-enhanced MRI of the brain and spinal cord in early relapsing-remitting multiple sclerosis. $\mathrm{Neu}$ rology 46: 373-378.

Tiberio M, Chard DT, Altmann DR, Davies G, Griffin CM, McLean MA, Rashid W, Sastre-Garriga J, Thompson AJ, Miller DH. 2006. Metabolite changes in early relapsingremitting multiple sclerosis: A two year follow-up study. $J$ Neurol 253: 224-230.

Tisell A, Leinhard OD, Warntjes JBM, Aalto A, Smedby Ö, Landtblom AM, Lundberg P. 2013. Increased concentrations of glutamate and glutamine in normal-appearing white matter of patients with multiple sclerosis and normal MR imaging brain scans. PLoS ONE 8: 1-8.

Truyen $\mathrm{L}$, van Waesberghe JH, van Walderveen MA, van Oosten BW, Polman CH, Hommes OR, Adèr HJ, Barkhof F. 1996. Accumulation of hypointense lesions ("black holes") on T1 spin-echo MRI correlates with disease progression in multiple sclerosis. Neurology 47: 1469-1476. 
Tsivgoulis G, Katsanos AH, Grigoriadis N, Hadjigeorgiou GM, Heliopoulos I, Kilidireas C, Voumvourakis K. 2015. The effect of disease modifying therapies on brain atrophy in patients with relapsing-remitting multiple sclerosis: A systematic review and meta-analysis. PLoS ONE 10: e0116511.

Van de Pavert SHP, Muhlert N, Sethi V, Wheeler-Kingshott CA, Ridgway GR, Geurts JJG, Ron M, Yousry TA, Thompson AJ, Miller DH, et al. 2015. DIR-visible grey matter lesions and atrophy in multiple sclerosis: Partners in crime? J Neurol Neurosurg Psychiatry 87: 461-467.

Van Hecke W, Nagels G, Leemans A, Vandervliet E, Sijbers J, Parizel PM. 2010. Correlation of cognitive dysfunction and diffusion tensor MRI measures in patients with mild and moderate multiple sclerosis. J Magn Reson Imaging 31: 1492-1498.

van Walderveen MAA, Kamphorst W, Scheltens P, van Waesberghe JHTM, Ravid R, Valk J, Polman CH, Barkhof F. 1998. Histopathologic correlate of hypointense lesions on T1-weighted spin-echo MRI in multiple sclerosis. Neurology 50: 1282-1288.

van Walderveen MA, Lycklama à Nijeholt GJ, Adèr HJ, Jongen PJ, Polman CH, Castelijns JA, Barkhof F. 2001. Hypointense lesions on T1-weighted spin-echo magnetic resonance imaging: Relation to clinical characteristics in subgroups of patients with multiple sclerosis. Arch Neurol 58: 76-81.

Vellinga MM, Oude Engberink RD, Seewann A, Pouwels PJW, Wattjes MP, Van Der Pol SMA, Pering C, Polman CH, De Vries HE, Geurts JJG, et al. 2008. Pluriformity of inflammation in multiple sclerosis shown by ultra-small iron oxide particle enhancement. Brain 131: 800-807.

Vural G, Keklikoğlu HD, Temel Ş, Deniz O, Ercan K. 2013. Comparison of double inversion recovery and conventional magnetic resonance brain imaging in patients with multiple sclerosis and relations with disease disability. Neuroradiol J 26: 133-142.

Walsh AJ, Blevins G, Lebel RM, Seres P, Emery DJ, Wilman AH. 2014. Longitudinal MR imaging of iron in multiple sclerosis: An imaging marker of disease. Radiology 270: 186-196

Wang Y, Sun P, Wang Q, Trinkaus K, Schmidt RE, Naismith RT, Cross AH, Song SK. 2015. Differentiation and quantification of inflammation, demyelination and axon injury or loss in multiple sclerosis. Brain 138: 1223-1238.

Wang C, Beadnall HN, Hatton SN, Bader G, Tomic D, Silva DG, Barnett MH. 2016. Automated brain volumetrics in multiple sclerosis: A step closer to clinical application. $J$ Neurol Neurosurg Psychiatry 87: 754-757.

Wattjes MP, Barkhof F. 2009. High field MRI in the diagnosis of multiple sclerosis: High field-high yield? Neuroradiology 51: 279-292.

Wattjes MP, Lutterbey GG, Harzheim M, Gieseke J, Träber F, Klotz L, Klockgether T, Schild HH. 2006. Higher sensitivity in the detection of inflammatory brain lesions in patients with clinically isolated syndromes suggestive of
Magnetic Resonance Imaging in Multiple Sclerosis

multiple sclerosis using high field MRI: An intraindividual comparison of 1.5 T with 3.0 T. Eur Radiol 16: 20672073.

Wattjes MP, Harzheim M, Lutterbey GG, Bogdanow M, Schild HH, Träber F. 2008. High field MR imaging and ${ }^{1} \mathrm{H}$-MR spectroscopy in clinically isolated syndromes suggestive of multiple sclerosis: Correlation between metabolic alterations and diagnostic MR imaging criteria. $J$ Neurol 255: 56-63.

Waubant E. 2006. Biomarkers indicative of blood-brain barrier disruption in multiple sclerosis. Dis Markers 22: 235244.

Weiner HL. 2009. The challenge of multiple sclerosis: How do we cure a chronic heterogeneous disease? Ann Neurol 65: 239-248

Welton T, Kent D, Constantinescu CS, Auer DP, Dineen RA. 2015. Functionally relevant white matter degradation in multiple sclerosis: A tract-based spatial meta-analysis. Radiology 275: 89-96.

Werring DJ. 2000. The pathogenesis of lesions and normalappearing white matter changes in multiple sclerosis: A serial diffusion MRI study. Brain 123: 1667-1676.

Wuerfel J, Sinnecker T, Ringelstein EB, Jarius S, Schwindt W, Niendorf T, Paul F, Kleffner I, Dorr J. 2012. Lesion morphology at 7 Tesla MRI differentiates Susac syndrome from multiple sclerosis. Mult Scler 18: 1592-1599.

Wylezinska M, Cifelli A, Jezzard P, Palace J, Alecci M, Matthews PM. 2003. Thalamic neurodegeneration in relapsing-remitting multiple sclerosis. Neurology 60: 19491954.

Yousuf F, Kim G, Tauhid S, Glanz B, Chu R, Tummala S, Healy B, Bakshi R. 2016. The contribution of cortical lesions to a magnetic resonance disease severity scale in multiple sclerosis. Front Neurol 7: 99.

Zackowski KM, Smith SA, Reich DS, Gordon-Lipkin E, Chodkowski BA, Sambandan DR, Shteyman M, Bastian AJ, Van Zijl PC, Calabresi PA. 2009. Sensorimotor dysfunction in multiple sclerosis and column-specific magnetization transfer-imaging abnormalities in the spinal cord. Brain 132: 1200-1209.

Ziemssen T, Derfuss T, DDe Stefano N, Giovannoni G, Palavra F, Tomic D, Vollmer T, Schippling S. 2015. Optimizing treatment success in multiple sclerosis. J Neurol 263: $1-13$.

Zivadinov R, Dwyer MG, Hussein S, Carl E, Kennedy C, Andrews M, Hojnacki D, Heininen-Brown M, Willis L, Cherneva M, et al. 2012a. Voxel-wise magnetization transfer imaging study of effects of natalizumab and IFNß-1a in multiple sclerosis. Mult Scler 18: 1125-1134.

Zivadinov R, Heininen-Brown M, Schirda C V, Poloni GU, Bergsland N, Magnano CR, Durfee J, Kennedy C, Carl E, Hagemeier J, et al. 2012b. Abnormal subcortical deepgray matter susceptibility-weighted imaging filtered phase measurements in patients with multiple sclerosis. A case-control study. Neuroimage 59: 331-339. 


\section{$\&_{\mathrm{CSH}}^{\infty} \&$ Cold Spring Harbor

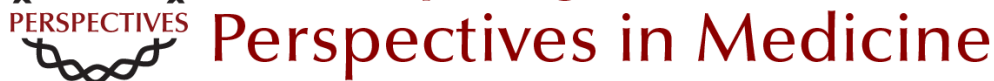

\section{Magnetic Resonance Imaging in Multiple Sclerosis}

Christopher C. Hemond and Rohit Bakshi

Cold Spring Harb Perspect Med 2018; doi: 10.1101/cshperspect.a028969 originally published online January 22, 2018

\section{Subject Collection Multiple Sclerosis}

Multiple Sclerosis Pathology

Hans Lassmann

Regulatory T Cells: From Discovery to

Autoimmunity

Alexandra Kitz, Emily Singer and David Hafler

The Multiple Roles of B Cells in Multiple Sclerosis

and Their Implications in Multiple Sclerosis

Therapies

Rui Li and Amit Bar-Or

Autologous Hematopoietic Stem Cell

Transplantation in the Treatment of Multiple

Sclerosis

Carolina A. Rush, Harold L. Atkins and Mark S.

Freedman

B-Cell Therapies in Multiple Sclerosis

Joseph J. Sabatino, Jr., Scott S. Zamvil and Stephen L. Hauser

Oral Therapies for Multiple Sclerosis Simon Faissner and Ralf Gold

Interferon $\beta$ for Multiple Sclerosis

Dejan Jakimovski, Channa Kolb, Murali

Ramanathan, et al.

Alemtuzumab as Treatment for Multiple Sclerosis Serafeim Katsavos and Alasdair Coles

\author{
Natalizumab: Perspectives from the Bench to \\ Bedside \\ Afsaneh Shirani and Olaf Stüve \\ Daclizumab Therapy for Multiple Sclerosis \\ Bibiana Bielekova
}

\section{Lifestyle and Environmental Factors in Multiple \\ Sclerosis \\ Lars Alfredsson and Tomas Olsson \\ Biomarkers in Multiple Sclerosis \\ Anu Paul, Manuel Comabella and Roopali Gandhi}

The Evolving Mechanisms of Action of Glatiramer

Acetate

Thomas Prod'homme and Scott S. Zamvil

Regulation of Astrocyte Functions in Multiple Sclerosis

Michael A. Wheeler and Francisco J. Quintana

Experimental Autoimmune Encephalomyelitis

(EAE) as Animal Models of Multiple Sclerosis (MS)

Simon Glatigny and Estelle Bettelli

Neurodegeneration in Progressive Multiple

Sclerosis

Graham Campbell and Don Mahad

For additional articles in this collection, see http://perspectivesinmedicine.cshlp.org/cgi/collection/ 